\title{
Insulin and $\alpha$-Tocopherol Enhance the Protective Effect of Each Other on Brain Cortical Neurons under Oxidative Stress Conditions and in Rat Two-Vessel Forebrain Ischemia/Reperfusion Injury
}

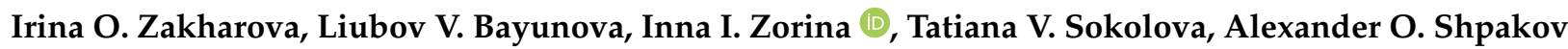 \\ and Natalia F. Avrova*
}

Citation: Zakharova, I.O.; Bayunova L.V.; Zorina, I.I.; Sokolova, T.V.; Shpakov, A.O.; Avrova, N.F. Insulin and $\alpha$-Tocopherol Enhance the Protective Effect of Each Other on Brain Cortical Neurons under Oxidative Stress Conditions and in Rat Two-Vessel Forebrain Ischemia/Reperfusion Injury. Int. J. Mol. Sci. 2021, 22, 11768. https:// doi.org/10.3390/ijms222111768

Academic Editor: Atsushi Matsuzawa

Received: 28 September 2021

Accepted: 27 October 2021

Published: 29 October 2021

Publisher's Note: MDPI stays neutral with regard to jurisdictional claims in published maps and institutional affiliations.

Copyright: (c) 2021 by the authors. Licensee MDPI, Basel, Switzerland. This article is an open access article distributed under the terms and conditions of the Creative Commons Attribution (CC BY) license (https:// creativecommons.org/licenses/by/ $4.0 /)$
I.M. Sechenov Institute of Evolutionary Physiology and Biochemistry, Russian Academy of Sciences, 194223 St. Petersburg, Russia; zakhar@iephb.ru (I.O.Z.); bayunova@iephb.ru (L.V.B.); carry111@yandex.ru (I.I.Z.); sokolova@iephb.ru (T.V.S.); alex_shpakov@list.ru (A.O.S.)

* Correspondence: avrova@iephb.ru

Abstract: Clinical trials show that insulin administered intranasally is a promising drug to treat neurodegenerative diseases, but at high doses its use may result in cerebral insulin resistance. Identifying compounds which could enhance the protective effects of insulin, may be helpful to reduce its effective dose. Our aim was thus to study the efficiency of combined use of insulin and $\alpha$-tocopherol $(\alpha-\mathrm{T})$ to increase the viability of cultured cortical neurons under oxidative stress conditions and to normalize the metabolic disturbances caused by free radical reaction activation in brain cortex of rats with two-vessel forebrain ischemia/reperfusion injury. Immunoblotting, flow cytometry, colorimetric, and fluorometric techniques were used. $\alpha$-T enhanced the protective and antioxidative effects of insulin on neurons in oxidative stress, their effects were additive. At the late stages of oxidative stress, the combined action of insulin and $\alpha$-T increased Akt-kinase activity, inactivated GSK-3beta and normalized ERK1/2 activity in cortical neurons, it was more effective than either drug action. In the brain cortex, ischemia/reperfusion increased the lipid peroxidation product content and caused $\mathrm{Na}^{+}, \mathrm{K}^{+}$-ATPase oxidative inactivation. Co-administration of insulin (intranasally, $0.25 \mathrm{IU} / \mathrm{rat}$ ) and $\alpha-\mathrm{T}$ (orally, $50 \mathrm{mg} / \mathrm{kg}$ ) led to a more pronounced normalization of the levels of Schiff bases, conjugated dienes and trienes and $\mathrm{Na}^{+}, \mathrm{K}^{+}$-ATPase activity than administration of each drug alone. Thus, $\alpha$-T enhances the protective effects of insulin on cultured cortical neurons in oxidative stress and in the brain cortex of rats with cerebral ischemia/reperfusion injury.

Keywords: insulin; $\alpha$-tocopherol; protection; cortical neurons; oxidative stress; brain cortex; forebrain ischemia; reperfusion

\section{Introduction}

Co-administration of various neuroprotective agents that are capable of enhancing each other's protective effects by modulating intracellular signaling pathways can significantly increase the ability of organisms to prevent the development of neuropathies in neurodegenerative, ischemic, or diabetic brain lesions. This is especially important in the case of insulin, since long-term exposure to high concentrations of this hormone leads to insulin resistance, it was shown to be characteristic for type 2 diabetes mellitus, Alzheimer's and Parkinson's diseases and other endocrine pathologies [1-3]. In accordance with the above, an urgent task for neurochemistry and neuroendocrinology is the search for endogenous regulators and natural substances, which could make it possible to reduce the pharmacological doses of insulin without causing a decrease in its neuroprotective effect.

Insulin is currently one of the most promising neuroprotective agents that are widely used in clinical trials. In pathological conditions such as type 2 diabetes mellitus, metabolic syndrome, Alzheimer's and Parkinson's diseases, the insulin level is increased markedly in 
blood, while in the brain, on the contrary, it is markedly diminished, which leads to disruption of insulin signaling in the hypothalamus and other regions of the brain [4-7]. Decreased levels of insulin in the brain and central insulin resistance lead to impaired metabolism and functional activity of neurons, as well as to the changes in hypothalamic regulation of carbohydrate and lipid metabolism, food intake and endocrine functions [8-10].

One of the most promising ways to correct insulin deficiency in the brain is its intranasal administration, since in this case the hormone enters the brain directly with the participation of cells of the olfactory and trigeminal nerves, bypassing the blood-brain barrier $[11,12]$. The neuroprotective effect of intranasally administered insulin is supported by numerous studies on the prevention of neurodegenerative brain damage in experimental animals $[1,13,14]$. The use of intranasally administered insulin for the treatment of patients with Alzheimer's disease and mild cognitive deficits leads to a significant improvement in their cognitive functions (see, for example, [15-19]). The clinical trials of intranasally administered insulin as a drug for the treatment of Parkinson's disease are also in progress [20].

There is reason to believe that intranasally administered insulin can have a neuroprotective effect in the case of cerebral ischemia, but information on this is extremely scarce. There are only our previous works on the ability of intranasally administered insulin to normalize metabolism and redox processes in the ischemic and reperfused brain [21,22]. Recently, a protective effect of intracerebroventricularly administered insulin on the viability of brain neurons in gerbils with global ischemia followed by reperfusion has been shown [23]. Ischemic brain damage is much more pronounced in rats with diabetes mellitus than in healthy animals, as a result of which systemic treatment of diabetic animals with insulin weakened the severity of ischemic lesions [24,25]. There are numerous studies, the authors of which have shown the protective effect of intranasally administered insulin-like growth factor-1 (IGF-1) in animals with focal and global ischemia (see, for example [26-28]). At the same time, in their review article, Lioutas and coauthors [29] noted that intranasally administered insulin is a more promising neuroprotector than IGF-1 as a drug for preventing severe consequences of ischemic brain damage, including acute ischemic stroke.

Among the compounds that may enhance the neuroprotective effect of insulin, $\alpha$ tocopherol $(\alpha-\mathrm{T})$, the main and most active component of vitamin $\mathrm{E}$, one of the natural components of various brain cells, is of particular interest (see, for example, [30-32]). In one of the recent mini-reviews [32] it is emphasized that targeting insulin resistance may be a breakthrough strategy to treat Alzheimer's disease. It is of interest that vitamin $\mathrm{E}$ and $C$ are considered to be able to decrease insulin resistance due to their antioxidant effects [32]. High doses of $\alpha$-T or vitamin E are usually used in clinical trials to improve cognitive function in Alzheimer's patients. It is important to note that peripheral $\alpha-\mathrm{T}$ levels in patients with Alzheimer's disease and mild cognitive impairment were lower than in healthy people, with the difference being quite significant [33]. These data suggest a relationship between vitamin $\mathrm{E}$ and $\alpha$-T content in diet and the risk of developing Alzheimer's disease and age-related cognitive deficit.

The aim of our work is to test the hypothesis that insulin and $\alpha$-T can significantly enhance the neuroprotective effects of each other in the in vitro and in vivo experiments. We studied the neuroprotective, antiapoptotic and antioxidant effects of insulin and $\alpha-\mathrm{T}$ on brain cortical neurons under conditions of oxidative stress, comparing the effects of individual drugs with the effects of their combined use. To elucidate the possible molecular mechanism of the additive neuroprotective action of insulin and $\alpha-\mathrm{T}$, the individual and joint effects of these neuroprotectors on the activity of protein kinase B (Akt), glycogen synthase kinase-3beta (GSK-3beta) and extracellular signal-regulated kinase 1/2 (ERK1/2) were studied. In the in vivo experiments, the ability of intranasally administered insulin and orally administered $\alpha$-T to prevent or reduce the increased accumulation of different lipid peroxidation (LPO) products as well as oxidative inactivation of $\mathrm{Na}^{+}, \mathrm{K}^{+}$-ATPase in the cerebral cortex of rats with two-vessel forebrain ischemia and subsequent reperfusion 
was investigated. In this case, a comparative study of monotherapy and combined therapy with these drugs was carried out. Our data indicate that insulin and $\alpha$-T are able to enhance the protective effects of each other on cortical neurons under conditions of oxidative stress and on the cells of the cerebral cortex of rats with ischemia/reperfusion injury.

\section{Results}

2.1. Additivity of Protective Effects of Insulin and $\alpha$-Tocopherol on Viability of Rat Brain Cortical Neurons Exposed to Hydrogen Peroxide

The treatment of cultured brain cortical neurons with $1 \mu \mathrm{M}$ insulin and $50 \mu \mathrm{M} \alpha$-T led to an increase in their viability under the conditions of oxidative stress induced by $100 \mu \mathrm{M}$ hydrogen peroxide. The protective effects of insulin and $\alpha$-T on neurons were found to be additive. The viability of neurons in the presence of both protectors was significantly higher than their viability in the presence of either insulin or $\alpha$-T alone (Figure 1).

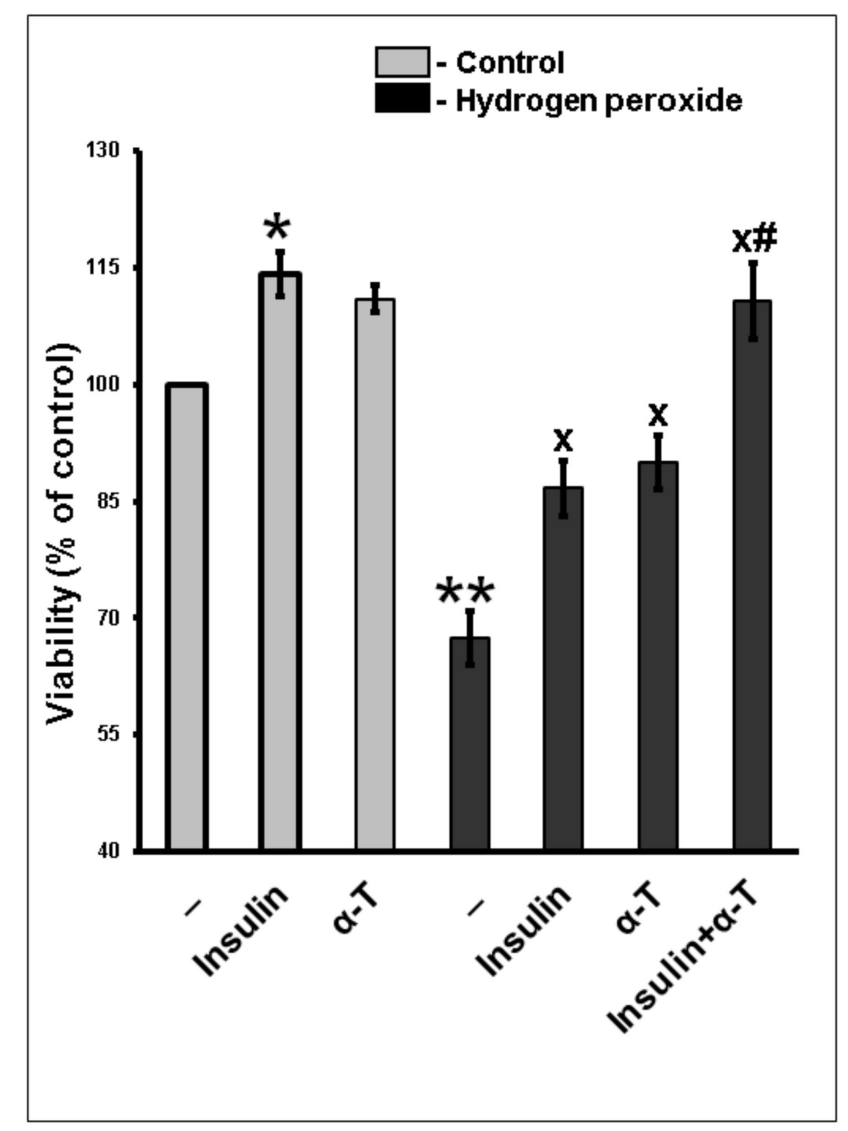

Figure 1. The additive protective effect of insulin and $\alpha$-tocopherol $(\alpha-\mathrm{T})$ on the viability of rat brain cortical neurons exposed to hydrogen peroxide. The data of 5-7 experiments are presented as the means \pm SEM. The neuronal viability was determined using 3-(4,5-dimethy-2-thiazolyl)-2,5-diphenyl$2 \mathrm{H}$-tetrazolium bromide (MTT) method. Abbreviations used: $\alpha$-tocopherol $(\alpha-\mathrm{T})$. Cortical neurons were pre-incubated for $1 \mathrm{~h}$ with $1 \mu \mathrm{M}$ insulin or for $18 \mathrm{~h}$ with $50 \mu \mathrm{M} \alpha$-T or with both compounds or without them. Then the neurons were exposed to $100 \mu \mathrm{M}$ hydrogen peroxide for $6 \mathrm{~h}$. The differences are significant according to one-way analysis of variance (ANOVA) followed by Tukey's test for multiple comparisons as compared: * - to control, $x$ - to the effect of hydrogen peroxide alone, \#- to the effect of either insulin, or $\alpha$-T alone, ${ }^{*} p<0.05,{ }^{* *} p<0.01$. in all other cases $p<0.01$.

Thus, the data obtained provide evidence that insulin and $\alpha$-T enhance the protective effect of each other on brain cortical neurons under oxidative stress conditions, increasing the viability of these cells. 
2.2. Antiapoptotic Effect of Insulin Plus $\alpha$-T on Rat Brain Cortical Neurons Exposed to Hydrogen Peroxide Is Higher than the Effects of Each Drug

Apoptosis and necrosis are the most common neuronal death pathways under oxidative stress conditions. In order to show that apoptotic death occurred as a result of cortical neuron exposure to $100 \mu \mathrm{M}$ hydrogen peroxide, the level of 17-19 $\mathrm{kDa}$ fragment of caspase- 3 was analyzed. Its accumulation shows the cleavage and activation of this enzyme. In brain cortical neurons, the pronounced increase of cleaved caspase-3 level and hence of caspase- 3 activation was observed $6 \mathrm{~h}$ after the initiation of oxidative stress by $100 \mu \mathrm{M}$ hydrogen peroxide (Figure 2A,B). Pre-incubation with $1 \mu \mathrm{M}$ insulin decreased the level of cleaved caspase- 3 , while the effect of $50 \mu \mathrm{M} \alpha$-T was not observed. In the case of pre-incubation with both insulin and $\alpha-T$, the decrease of cleaved caspase- 3 level (and hence of neuronal apoptotic death) was more pronounced than in the case of pre-incubation with each of the protectors $6 \mathrm{~h}$ after application of hydrogen peroxide to the neurons $(p<0.01$ by paired Student's $t$-test). Even 15 min after the addition of pro-oxidant to cortical neurons, their pre-incubation with insulin plus $\alpha$-T resulted in a significant decrease in cleaved caspase-3 level and hence of neuronal apoptotic death, while the addition of insulin or $\alpha$-T alone had no effect on the neuronal apoptotic death (Figure 2B).
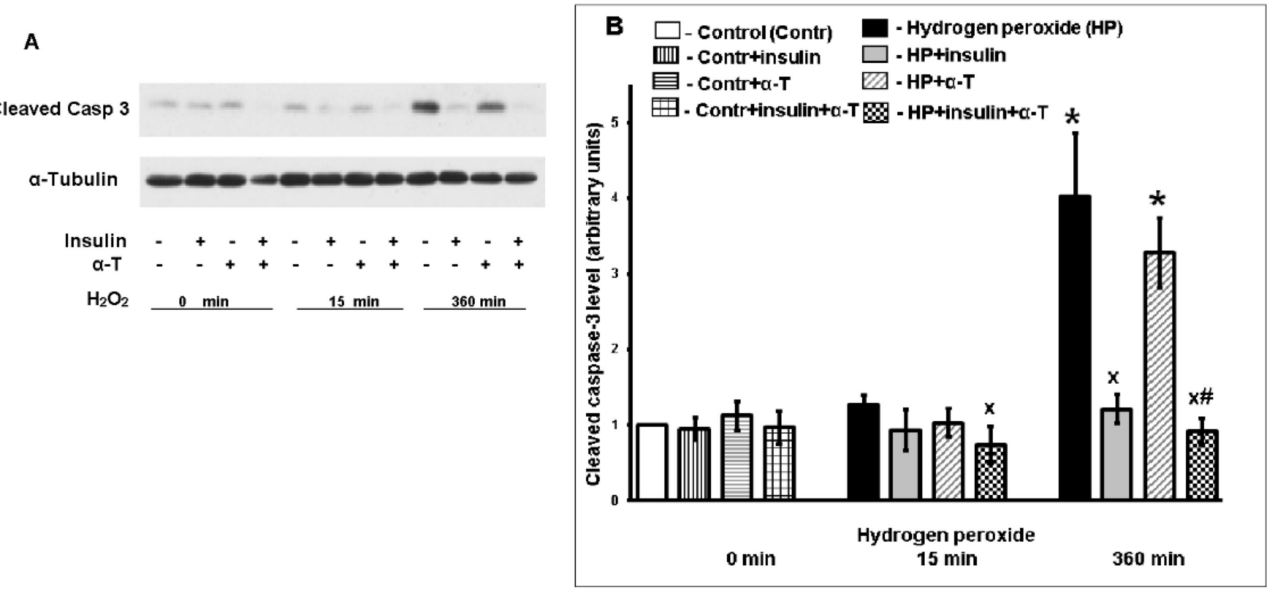

Figure 2. The antiapoptotic effect of insulin plus $\alpha$-T on rat brain cortical neurons exposed to hydrogen peroxide is more pronounced than the effect of each drug. (A) immunoblots of cleaved caspase-3 are shown. (B) the data of 10 experiments are presented as the means \pm SEM. Abbreviations used: Casp3-caspase-3. Cortical neurons were pre-incubated for $1 \mathrm{~h}$ with $1 \mu \mathrm{M}$ insulin or for $18 \mathrm{~h}$ with $50 \mu \mathrm{M} \alpha$-T or with both drugs or without them. Then the neurons were exposed to $100 \mu \mathrm{M}$ hydrogen peroxide for $0,15 \mathrm{~min}$ and $6 \mathrm{~h}$. The differences are significant according to Student's paired $t$-test as compared: * - to control, $\mathrm{x}$ - to the effect of hydrogen peroxide alone, \#-to the effect of either insulin or $\alpha$-T alone, $p<0.01$ in all cases.

\subsection{Antioxidative Effect of Insulin Plus $\alpha$-T on Rat Brain Cortical Neurons Exposed to Hydrogen Peroxide Is Higher than the Effects of Each Drug}

Pre-incubation of brain cortical neurons with $50 \mu \mathrm{M} \alpha$-T or $1 \mu \mathrm{M}$ insulin diminished the formation of reactive oxygen species (ROS) in these cells induced by hydrogen peroxide exposition. The results of a typical experiment are shown in Figure 3. The use of insulin plus $\alpha$-T was more effective than insulin or $\alpha$-T alone $(p<0.05)$.

\subsection{Effect of Insulin and $\alpha-T$ on Activity of Protein Kinase B (Akt) in Control and Hydrogen Peroxide-Exposed Brain Cortical Neurons}

To assess the mechanisms of $\alpha$-T-enhancing effect on insulin-induced neuroprotection in cortical neurons, we compared the combined and separate effects of these drugs on the activity of the protein kinases Akt, GSK-3beta and ERK1/2. The activity of Akt was assessed using Western blotting, for which the level of Ser ${ }^{473}$ - and $\mathrm{Thr}^{308}$-phosphorylated 
forms of Akt kinase was measured using monoclonal antibodies specific for pAkt (Ser ${ }^{473}$ ) and pAkt $\left(\mathrm{Thr}^{308}\right)$, respectively. The data obtained showed that insulin and hydrogen peroxide increased the phosphorylation of both residues. Nevertheless, the intensity of $\mathrm{Thr}^{308}$-phosphorylation was less pronounced than the intensity of Ser ${ }^{473}$-phosphorylation, so further experiments were carried out mainly using antibodies against pAkt (Ser $\left.{ }^{473}\right)$.

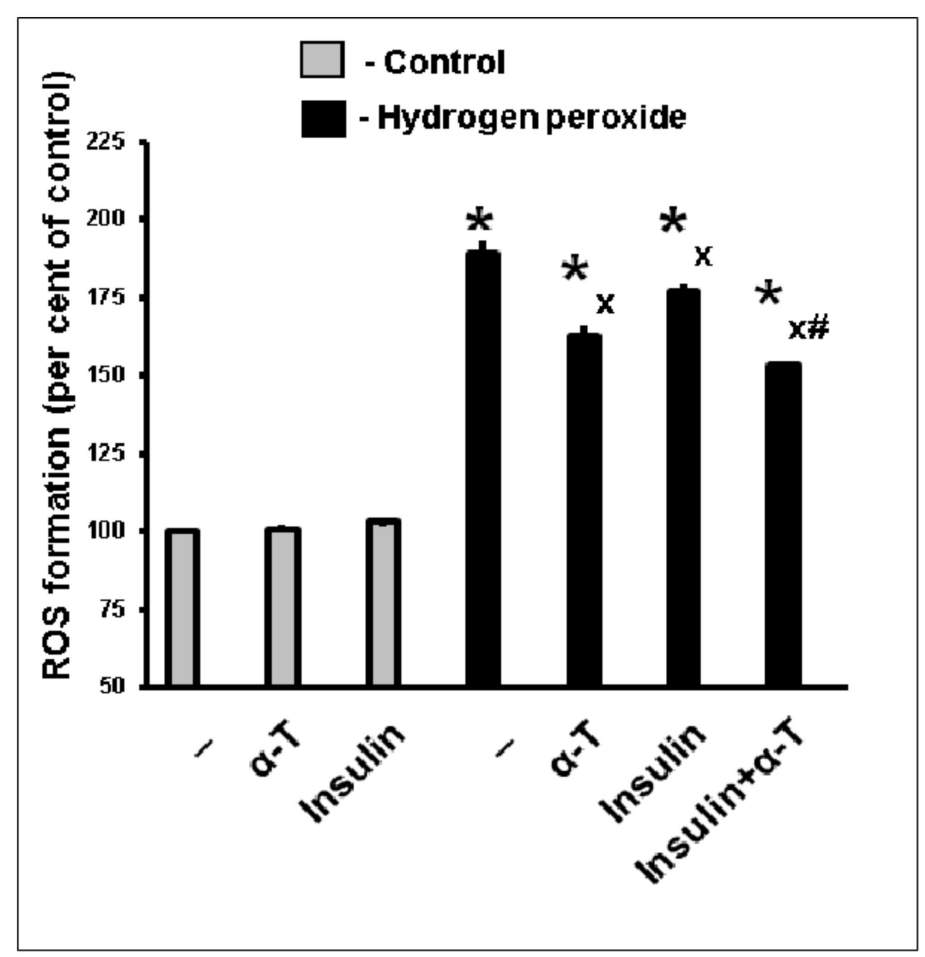

Figure 3. The pre-incubation with insulin or $\alpha$-T or with both drugs diminishes the formation of ROS in brain cortical neurons exposed to hydrogen peroxide. The data of one typical experiment from five experiments made are given as the means \pm SEM. Cortical neurons were pre-incubated for $1 \mathrm{~h}$ with $1 \mu \mathrm{M}$ insulin or for $18 \mathrm{~h}$ with $50 \mu \mathrm{M} \alpha$-T or with both drugs or without them. Then the neurons were exposed to $100 \mu \mathrm{M}$ hydrogen peroxide for $1 \mathrm{~h}$. The differences are significant according to Student's $t$-test as compared to: *-control, $x$ —-the effect of hydrogen peroxide alone, \#-the effect of either insulin or $\alpha$-T alone, $p<0.05$ in all cases.

Hydrogen peroxide increased Akt activity $15 \mathrm{~min}$ after its addition to neurons but had no effect on Akt activity $6 \mathrm{~h}$ after its addition to these cells. At the same time, pre-incubation with insulin led to activation of Akt kinase both in control neurons and in neurons exposed to hydrogen peroxide for $15 \mathrm{~min}$ and $6 \mathrm{~h}$. It was shown that $1 \mu \mathrm{M}$ insulin increased the basal Akt activity more than four times. The effect of insulin plus $\alpha$-T was significantly higher than the effect of each of the drugs $6 \mathrm{~h}$ after pro-oxidant addition to the samples ( $p<0.01$ by paired Student's $t$-test) (Figure 4). It is of importance that insulin alone and to a greater extent in combination with $\alpha$-T could still increase the Akt activity when the Akt activating effect of hydrogen peroxide had already disappeared (Figure 4).

\subsection{Effect of Insulin and $\alpha$-T on $p G S K-3 b e t a\left(S^{9}{ }^{9}\right)$ Level in Control and Exposed to Hydrogen Peroxide Brain Cortical Neurons}

Akt activation by the drugs or pro-oxidants may lead to phosphorylation of GSK-3beta at the $\operatorname{Ser}^{9}$ and, as a result, inactivates this enzyme. $15 \mathrm{~min}$ after its addition to brain cortical neurons, hydrogen peroxide induced the activation of Akt kinase and increased the ratio pGSK-3beta (Ser $\left.{ }^{9}\right) /$ GSK-3beta. But had no effect $(p>0.05)$ on these enzymes $6 \mathrm{~h}$ after the induction of oxidative stress (Figures 4 and 5), The effect of insulin on both the pGSK-3beta level, and the Akt activity was much more pronounced and prolonged as compared to 
the effect of hydrogen peroxide (Figures 4 and 5). Insulin increased the ratio pGSK-3beta $\left(\mathrm{Ser}^{9}\right) /$ GSK-3beta in control neurons from 1.0 to $1.43 \pm 0.09(p<0.01)$. Under the conditions of oxidative stress, its ability to increase this ratio and hence to inactivate GSK-3beta was significant and pronounced ( $n=10, p<0.01$, paired Student's $t$-test, Figure 5B). In contrast to insulin, the ability of $\alpha$-T to inactivate GSK-3beta in control neurons and in neurons $15 \mathrm{~min}$ and $6 \mathrm{~h}$ after the application of pro-oxidant was not detected.

A

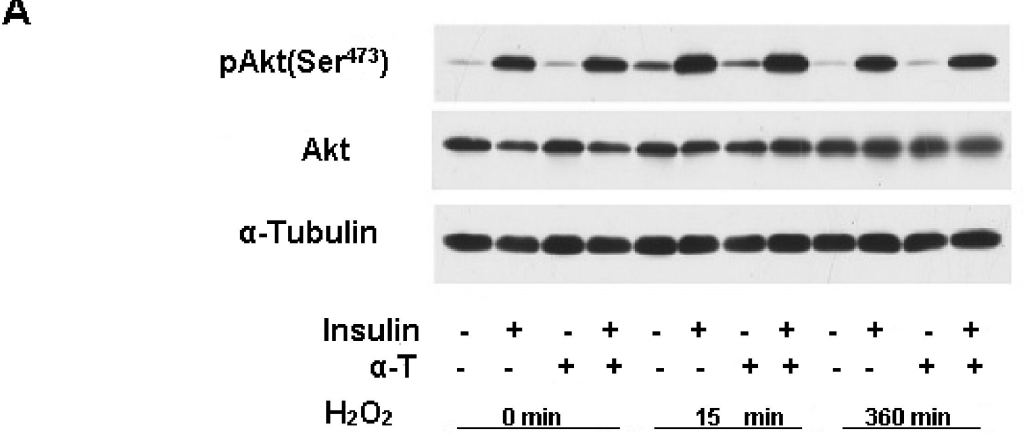

B

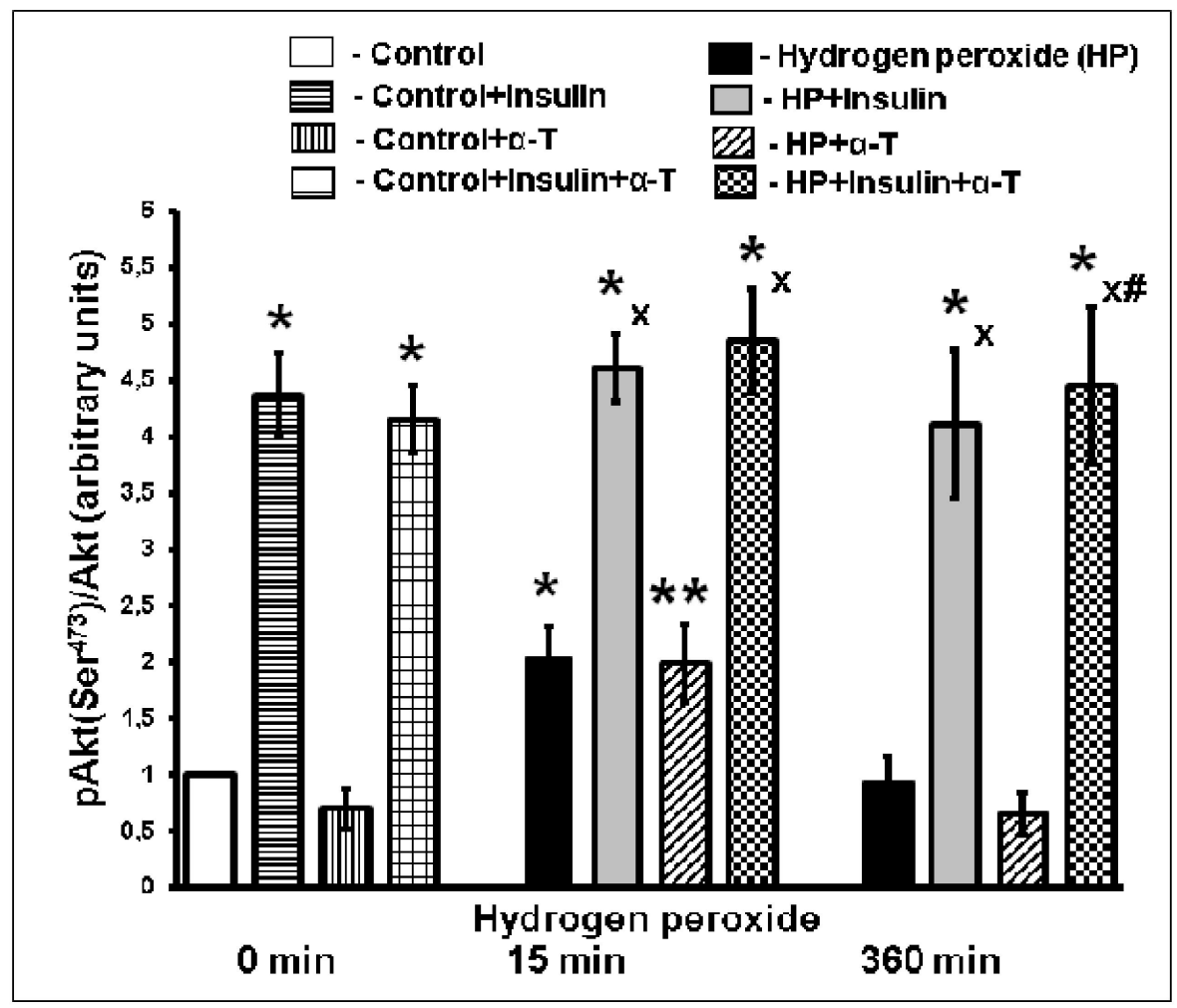

Figure 4. The effect of hydrogen peroxide, insulin and $\alpha$-T on the activity of Akt (pAkt (Ser $\left.\left.{ }^{473}\right) / \mathrm{Akt}\right)$ in brain cortical neurons. (A) immunoblots of pAkt $\left(\mathrm{Ser}^{473}\right)$ and total Akt are shown; (B) the data of 6 experiments are presented as the means \pm SEM. The brain cortical neurons were pre-incubated for $1 \mathrm{~h}$ with $1 \mu \mathrm{M}$ insulin or for $18 \mathrm{~h}$ with $50 \mu \mathrm{M} \alpha$-T or with both drugs or without them. Then the neurons were exposed to $100 \mu \mathrm{M}$ hydrogen peroxide for 0,15 and $360 \mathrm{~min}$. The differences are significant according to Student's paired $t$-test as compared: * and ${ }^{* *}$ - to the control, ${ }^{*} p<0.02$, ** $p<0.05 ; x$ - to the effect of hydrogen peroxide alone, $p<0.01$, \#- to the effect of insulin or $\alpha-\mathrm{T}$ alone, $p<0.01$.

$\alpha-T$ was found to enhance the effect of insulin $6 \mathrm{~h}$ after the induction of oxidative stress by hydrogen peroxide, the increase in pGSK-3beta $\left(\mathrm{Ser}^{9}\right)$ levels in cortical neurons was significantly higher when cells were incubated with insulin plus $\alpha$-T, as compared to incubation with insulin or $\alpha$-T alone ( $n=10, p<0.01$, paired Student's $t$-test). It means that 
insulin is able to inactivate GSK-3beta in the course of oxidative stress development, while alpha-T is able to enhance its effect at late stages of oxidative stress development. The activation of GSK-3beta negatively affects the function of mitochondria in cells, including neurons, which leads to a decrease in the mitochondrial membrane potential and the opening of the mitochondrial permeability transition pore (mPTP). Thus, the above-mentioned inhibitory effects of insulin on GSK-3beta activity and the ability of $\alpha$-T to enhance this effect appear to be of importance to provide their protective effects.

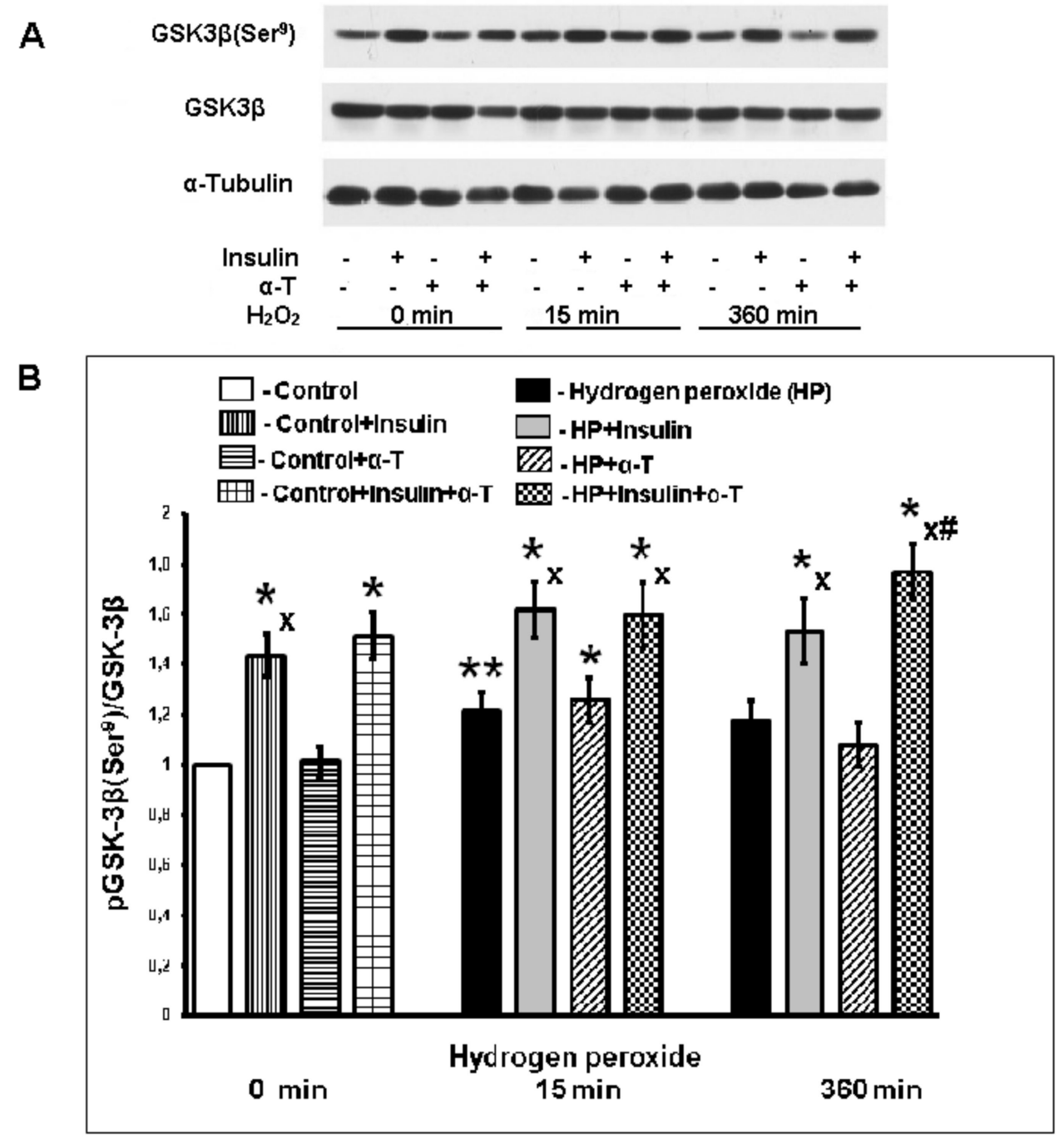

Figure 5. The effect of hydrogen peroxide, insulin and $\alpha$-T on the activity of protein kinase GSK-3beta [pGSK-3beta (Ser ${ }^{9}$ )/GSK-3beta] in brain cortical neurons. (A) immunoblots of pGSK-3beta (Ser ${ }^{9}$ ) and total GSK-3beta are shown; (B) the data of 10 experiments are presented as the means \pm SEM. The brain cortical neurons were pre-incubated for $1 \mathrm{~h}$ with $1 \mu \mathrm{M}$ insulin or for $18 \mathrm{~h}$ with $50 \mu \mathrm{M} \alpha$-T or with both drugs or without them. Then the neurons were exposed to $100 \mu \mathrm{M}$ hydrogen peroxide for 0,15 and $360 \mathrm{~min}$. The differences are significant according to Student's paired $t$-test as compared: * and ${ }^{* *}$ - to the control, ${ }^{*} p<0.02,{ }^{* *} p<0.05 ; x$-to the effect of hydrogen peroxide alone, $p<0.01$, \#-to the effect of insulin or $\alpha$-T alone, $p<0.01$.

\subsection{Effect of Insulin and $\alpha$-T on ERK1/2 Activity ( $p$ ERK1/2/ERK1/2 Ratio) in Control and Hydrogen Peroxide-Exposed Brain Cortical Neurons}

The modulation of ERK1/2 activity may be of importance for the ability of insulin and $\alpha$-T to increase the viability of cortical neurons. It was shown previously that short 
activation of ERK1/2 by the protectors increased the viability of nerve cells [34-37], but activation of ERK1/2 for long time promoted nerve cells death [36-38].

In the present study, hydrogen peroxide increased the ERK1/2 phosphorylation $15 \mathrm{~min}$ after its application to the neurons (Figure 6). Insulin increased the basal ERK1/2 activity and its activity $15 \mathrm{~min}$ after the application of hydrogen peroxide (Figure 6). At this point, $\alpha$-T effect was not detected. It was previously shown [39] that $\alpha$-T increased the ERK1/2 activity only 5 min after hydrogen peroxide addition to cortical neurons. Hydrogen peroxide caused a pronounced increase of ERK1/2 activity at late stages of oxidative stress development $-6 \mathrm{~h}$ after its application to the neurons (Figure 6). At this point, insulin and $\alpha$-T decreased the ERK1/2 activity $(n=10, p<0.05$ by paired Student's $t$-test). A decrease in the ERK1/2 activity was more pronounced in the case of insulin and $\alpha$-T combination, and the difference between the effect of insulin plus $\alpha$-T and the effects of insulin or $\alpha$-T alone was significant ( $n=10, p<0.02$ by paired Student's $t$-test).

A

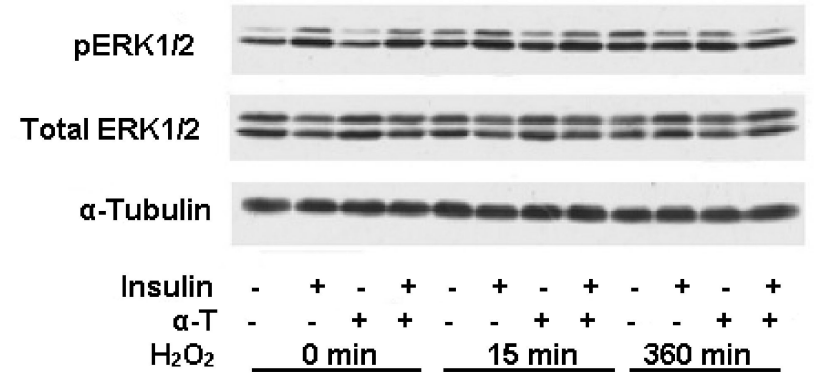

B

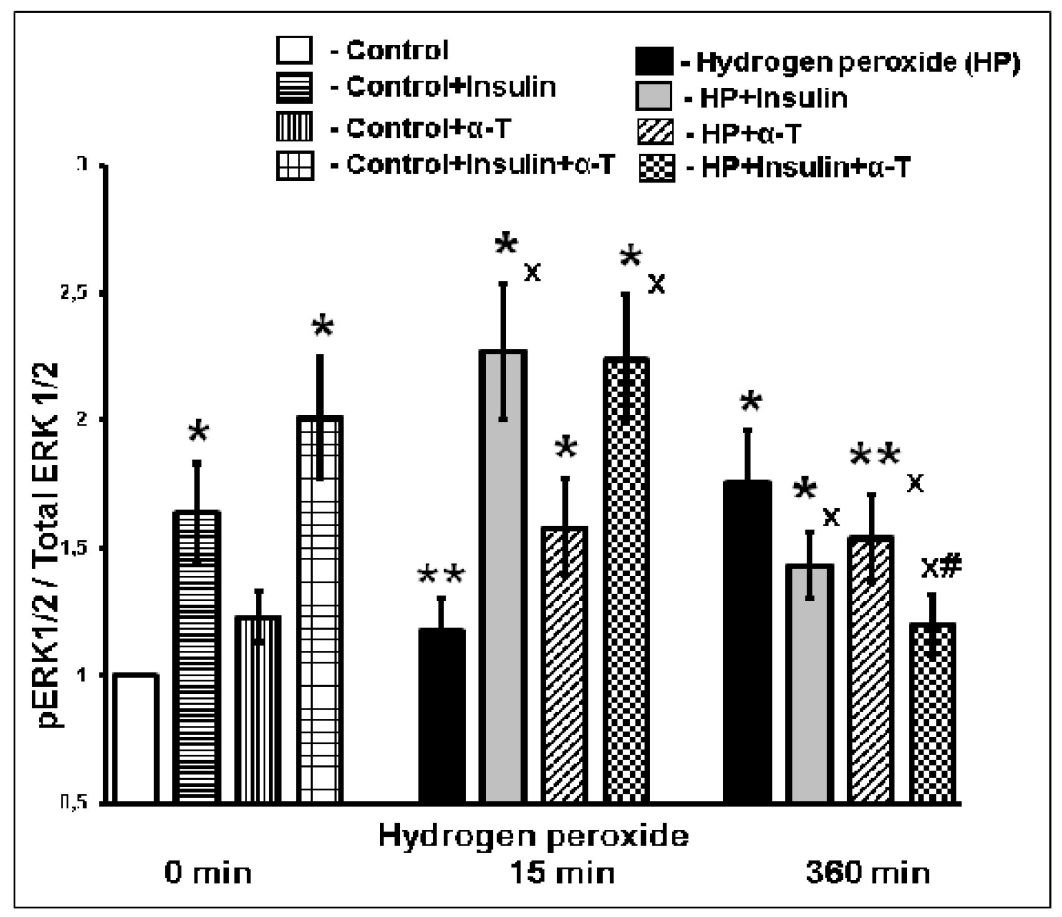

Figure 6. The effect of hydrogen peroxide, insulin and $\alpha-T$ on the activity of ERK $1 / 2$ (pERK1/2/ERK1/2 ratio) in brain cortical neurons. (A)-immunoblots of pERK1/2 and total ERK1/2 are shown; (B) - the data of 6 experiments are presented as the means \pm SEM. The brain cortical neurons were pre-incubated for $1 \mathrm{~h}$ with $1 \mu \mathrm{M}$ insulin or for $18 \mathrm{~h}$ with $50 \mu \mathrm{M} \alpha$ - $\mathrm{T}$, with both drugs or without them. Then the neurons were exposed to $100 \mu \mathrm{M}$ hydrogen peroxide for 0,15 and $360 \mathrm{~min}$. The differences are significant according to Student's paired $t$-test as compared: * and ** to the control, ${ }^{*} p<0.02,{ }^{* *} p<0.05 ; x$ — to the effect of hydrogen peroxide alone, $p<0.01$, \#— to the effect of insulin or $\alpha$-T alone, $p<0.01$. 


\subsection{Effect of Insulin and $\alpha$-T on Mitochondrial Membrane Potential in Control and Hydrogen Peroxide-Exposed Brain Cortical Neurons}

The exposure of brain cortical neurons to hydrogen peroxide markedly diminished the mitochondrial membrane potential $[\Delta \psi(\mathrm{m})]$ in brain cortical neurons-from $70.4 \pm 2.09$ arbitrary units in control neurons to $55.9 \pm 4.64$ arbitrary units in hydrogen peroxide-treated neurons $(p<0.05)$ (Table 1$)$. It was shown by flow cytometry that the pre-incubation of neurons with $50 \mu \mathrm{M} \alpha-\mathrm{T}$ or $1 \mu \mathrm{M}$ insulin or with both drugs for $20 \mathrm{~h}$ resulted in the marked and significant $(p<0.02)$ increase of mitochondrial membrane potential of brain cortical neurons (see Table 1). The increase of $\Delta \psi(\mathrm{m})$ was more pronounced if neurons were pre-incubated with insulin $+\alpha-\mathrm{T}$ than in the case of their pre-incubation with one of these protectors, the differences being significant $(p<0.01)$ (Table 1). Thus, $\alpha$-T was found to enhance the ability of insulin to increase $\Delta \psi(\mathrm{m})$ in neurons which was markedly diminished under conditions of oxidative stress.

Table 1. The effect of pre-incubation with insulin and $\alpha$-tocopherol $(\alpha-\mathrm{T})$ on mitochondrial membrane potential in brain cortical neurons exposed to hydrogen peroxide.

\begin{tabular}{cc}
\hline Sample & Mean \pm SEM \\
\hline Control & $71.1 \pm 2.88$ \\
\hline Control+Insulin & $67.5 \pm 0.15$ \\
\hline Control+ $\alpha$-T & $68.3 \pm 0.25$ \\
\hline Hydrogen peroxide (HP) & $55.9 \pm 4.64^{\mathrm{a}}$ \\
\hline HP+ Insulin & $78.3 \pm 0.72^{\mathrm{b}}$ \\
\hline HP+ $\alpha-\mathrm{T}$ & $68.0 \pm 0.36^{\mathrm{b}}$ \\
\hline HP+Insulin $+\alpha-\mathrm{T}$ & $89.0 \pm 2.36^{\mathrm{b}, \mathrm{c}}$
\end{tabular}

Abbreviations used: $\alpha$-tocopherol $(\alpha-\mathrm{T})$. Brain cortical neurons in culture were pre-incubated with $1 \mu \mathrm{M}$ insulin or with $50 \mu \mathrm{M} \alpha$-T or with both protectors or without them for $20 \mathrm{~h}$ and then exposed for $1 \mathrm{~h}$ to $100 \mu \mathrm{M}$ hydrogen peroxide. The data are given as the means \pm SEM of 4-5 determinations. The mitochondrial membrane potential was measured using TMRM on a Beckman Coulter Epics XL flow cytometer. The data obtained were expressed in arbitrary units. The differences are significant according to Student's $t$-test: ${ }^{a}$-as compared to control values, $p<0.05, \mathrm{~b}$ - as compared to the effect of hydrogen peroxide alone, $p<0.02$, c - as compared to the effect of hydrogen peroxide+insulin and hydrogen peroxide+ $\alpha$-T, $p<0.01$.

The histograms showing the control samples and the effect of hydrogen peroxide on cortical neurons in the absence of the protectors and after the pre-incubation with $1 \mu \mathrm{M}$ insulin or with $50 \mu \mathrm{M} \alpha$-T or with both compounds are given in Figure 7 .

2.8. The Combination of Intranasally Administered Insulin Together with Orally Administered $\alpha-T$ Diminished the Accumulation of Schiff Bases in the Brain Cortex of Rats with Ischemia/Reperfusion to Higher Extent than Monotherapy with These Drugs

We studied the ability of insulin, $\alpha$-T and their combinations to prevent or reduce metabolic disorders caused by the activation of free radical reactions in the cerebral cortex of rats with two-vessel forebrain ischemia and subsequent reperfusion. Two-vessel forebrain ischemia together with hypotension and subsequent reperfusion, led to a pronounced and significant increase in LPO products such as Schiff bases and conjugated dienes and trienes, and partially inactivated $\mathrm{Na}^{+}, \mathrm{K}^{+}$-ATPase in the cerebral cortex of rats. The ability of intranasally administered insulin and orally administered $\alpha$-T to normalize the accumulation of lipid peroxidation products (LPO) and prevent oxidative inactivation of $\mathrm{Na}^{+}, \mathrm{K}^{+}$-ATPase in the cerebral cortex during ischemia and reperfusion was investigated.

The content of Schiff bases increased more than two times in the brain cortex of rats with ischemia/reperfusion injury (Figure 8). The intranasally administered insulin $(0.25 \mathrm{IU} / \mathrm{rat})$ or orally administered $\alpha-\mathrm{T}(50 \mathrm{mg} / \mathrm{kg})$ decreased the content of Schiff bases $(p<0.01)$ (Figure 8). The administration of insulin plus $\alpha$-T to rats decreased the level of Schiff bases in brain cortex to a higher extent than administration of insulin or $\alpha$-T alone $(p<0.01)$ (Figure 8). 

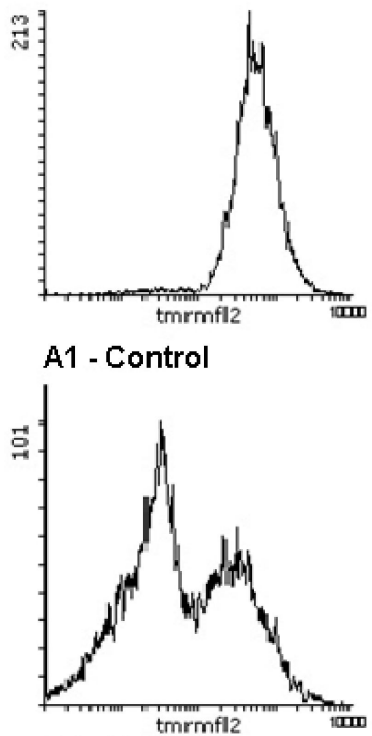

B1 $-\mathrm{H}_{2} \mathrm{O}_{2}$

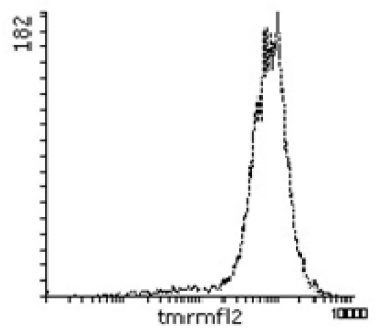

$\mathrm{C} 1$ - Insulin $+\mathrm{a}-\mathrm{T}+\mathrm{H}_{2} \mathrm{O}_{2}$

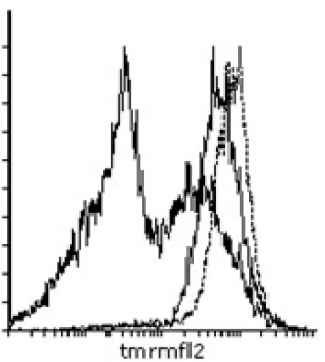

D1 - Overlay Histogram

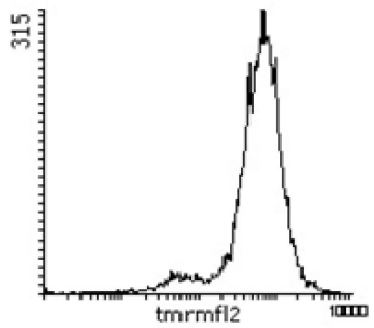

A2 - Control

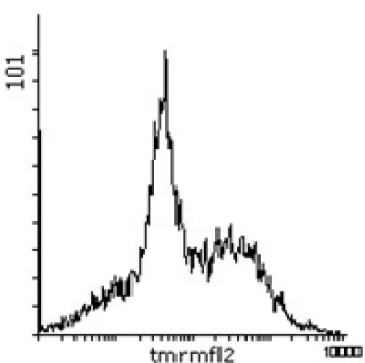

$\mathrm{B} 2-\mathrm{H}_{2} \mathrm{O}_{2}$

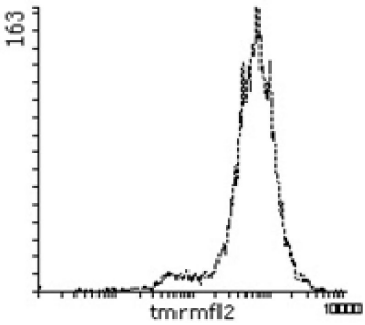

$\mathrm{C} 2$ - Insulin $+\mathrm{H}_{2} \mathrm{O}_{2}$

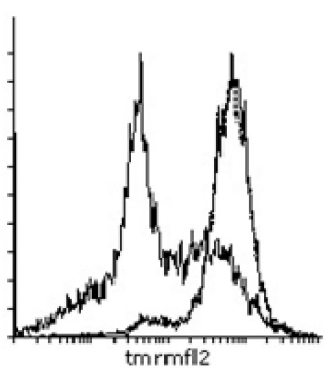

D2 - Overlay Histogram

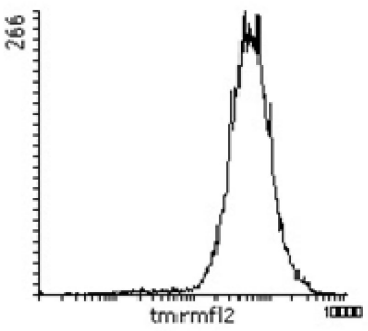

A3 - Control

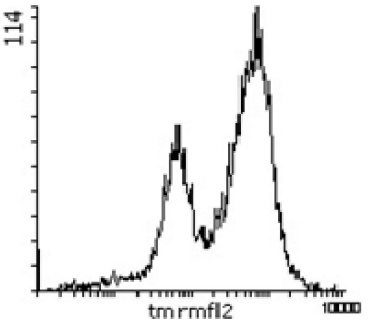

B3 - $\mathrm{H}_{2} \mathrm{O}_{2}$
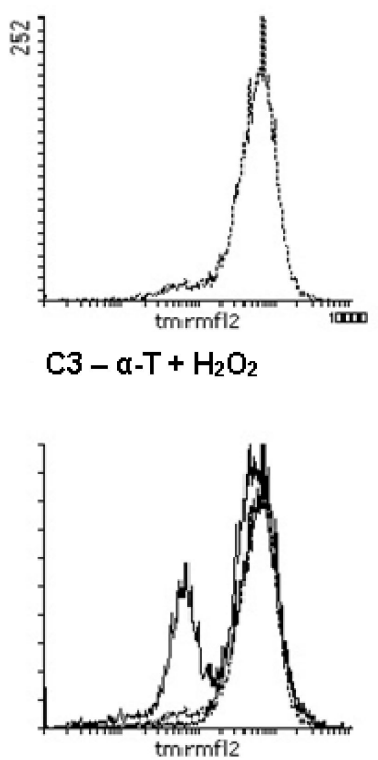

D3 - Overlay Histogram

Figure 7. The effect of hydrogen peroxide, insulin, $\alpha$-T and insulin plus $\alpha$-T on the mitochondrial membrane potential in cortical neurons (histograms obtained by flow cytometry). Cortical neurons were pre-incubated with $1 \mu \mathrm{M}$ insulin, $50 \mu \mathrm{M} \alpha$-T or with both compounds. Then neurons were exposed to $100 \mu \mathrm{M}$ hydrogen peroxide for $1 \mathrm{~h}$. A1, A2, A3-controls, B1, B2, B3-the effect of hydrogen peroxide alone, C1, C2, C3-the effect of hydrogen peroxide after pre-incubation of neurons with: $\mathrm{C} 1-1 \mu \mathrm{M}$ insulin and $50 \mu \mathrm{M} \alpha-\mathrm{T}, \mathrm{C} 2-1 \mu \mathrm{M}$ insulin, $\mathrm{C} 3-50 \mu \mathrm{M} \alpha-\mathrm{T}, \mathrm{D} 1, \mathrm{D} 2, \mathrm{D} 3-$ the overlay of the histograms presented in $\mathrm{A}, \mathrm{B}$ and $\mathrm{C}$.

2.9. The Combination of Intranasally Administered Insulin Together with Orally Administered $\alpha-T$ Normalizes the Level of Conjugated Dienes and Trienes in the Brain Cortex of Rats with Ischemia/Reperfusion to a Greater Extent than Monotherapy with These Drugs

The level of conjugated dienes was markedly higher (by 36.8\%) in the brain cortex of rats after ischemia and reperfusion as compared to sham-operated rats $(p<0.01)$. In the brain cortex of ischemic and reperfused rats which received either insulin (intranasally, $0.25 \mathrm{IU} / \mathrm{rat}$ ) or $\alpha-\mathrm{T}$ (orally, $50 \mathrm{mg} / \mathrm{kg}$ ), the level of conjugated dienes was higher by $21.3 \%$ and $23.1 \%$, respectively, as compared to sham-operated rats $(p<0.01)$ (Figure 9$)$. At the 
same time, if both insulin and $\alpha$-T were administered to rats with ischemic and reperfused forebrain in the above-mentioned doses, the level of conjugated dienes was not different from that in brain cortex of sham-operated rats (Figure 9). The additive effect of insulin and $\alpha$-T was observed, as the total effect of both protectors administered to ischemic and reperfused rats was approximately equal to the sum of insulin ad $\alpha$-T effects (Figure 9).

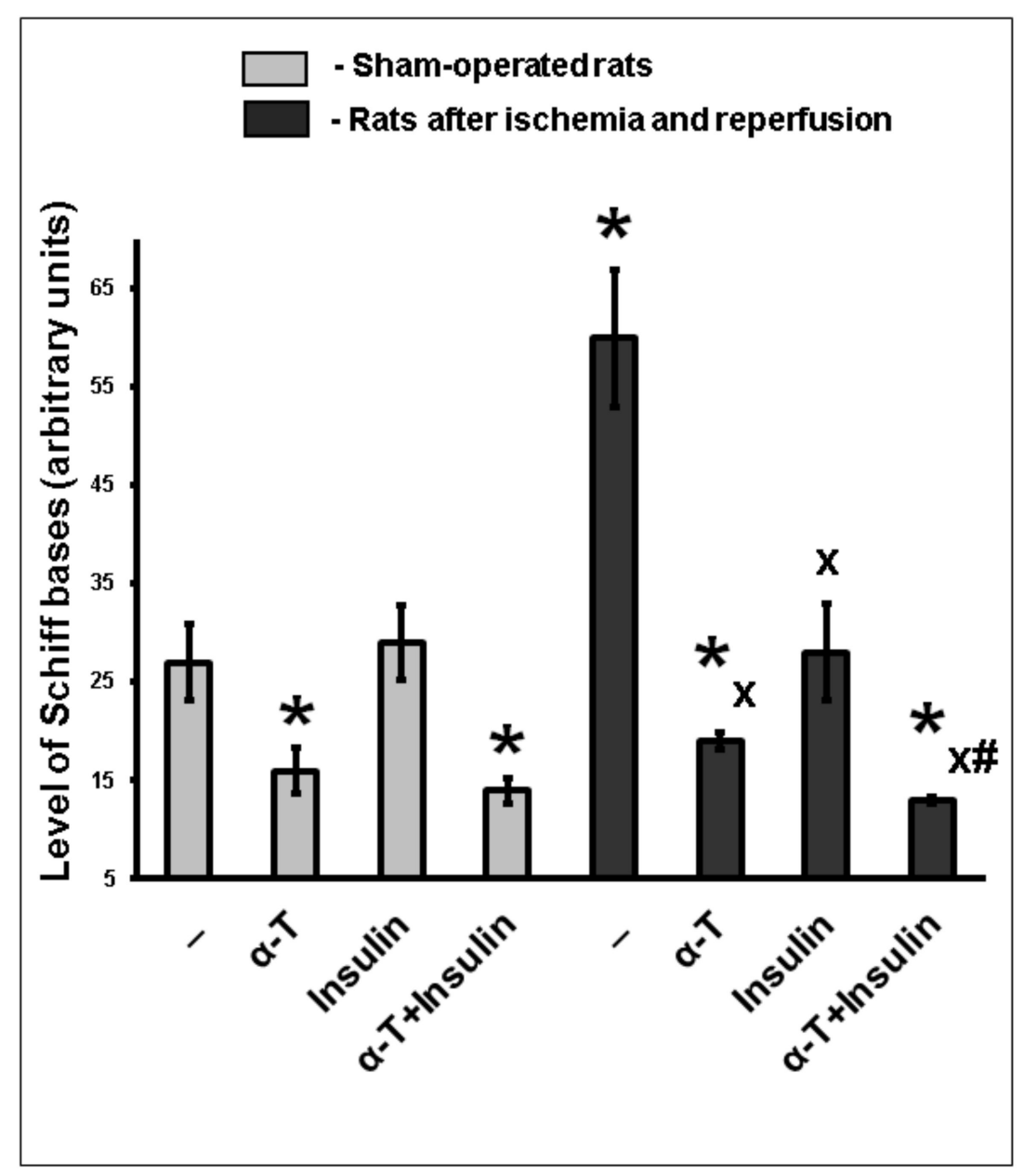

Figure 8. The effect of intranasally administered insulin and orally administered $\alpha$-T on the content of Schiff bases in the brain cortex of rats after two-vessel forebrain ischemia followed by reperfusion. The data of 5-7 experiments are presented as the means \pm SEM. The two-vessel ischemia was induced by ligation of carotid arteries for $20 \mathrm{~min}$ and hypotension, it was followed by reperfusion for $1 \mathrm{~h}$. Insulin was administered intranasally at a dose of $0.25 \mathrm{IU} /$ rat, while $\alpha$-T was given orally at a dose of $50 \mathrm{mg} / \mathrm{kg}$. The differences are significant according to Student's $t$-test as compared: * — to the control, $x$ - to the effect of ischemia and reperfusion, \#- to the effect of insulin and $\alpha$-T alone, $p<0.01$ in all cases.

The similar data were obtained when studying the level of conjugated trienes (Figure 10). The level of conjugated trienes was markedly increased (by $30.6 \%$ ) in ischemic and reperfused rat brain cortex as compared to sham-operated rats $(p<0.01)$. In the brain cortex of ischemic and reperfused rats which received either insulin (intranasally, $0.25 \mathrm{IU} / \mathrm{rat}$ ) or $\alpha-\mathrm{T}$ (orally, $50 \mathrm{mg} / \mathrm{kg}$ ), the level of conjugated dienes was higher by $24.3 \%$ and $27.2 \%$ as compared to sham-operated rats (Figure 10). In the brain cortex of rats with ischemic and reperfused forebrain treated with insulin plus $\alpha$-T, the levels of conjugated trienes did not differ from those in sham-operated rats (Figure 10). 


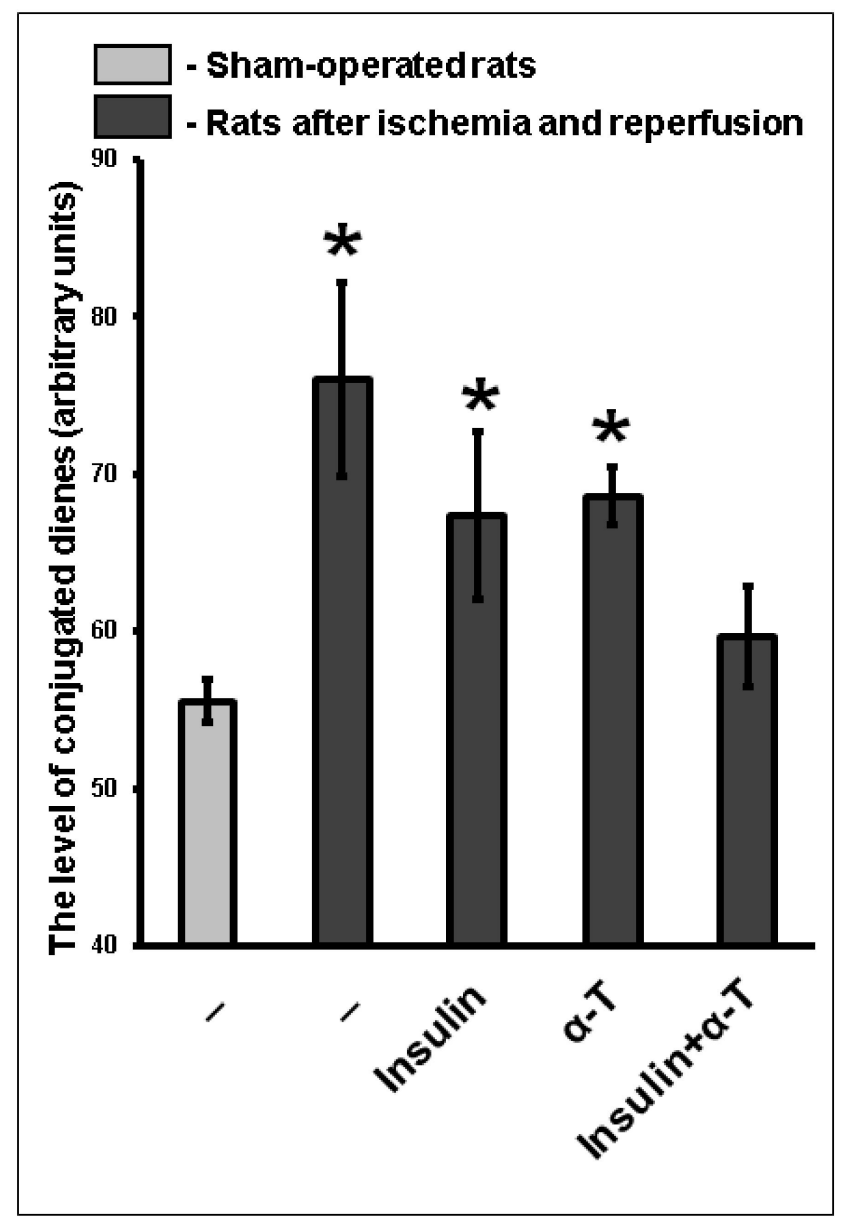

Figure 9. The effect of intranasally administered insulin and orally administered $\alpha$-T on the level of conjugated dienes in the brain cortex of rats with two-vessel forebrain ischemia followed by reperfusion. The data of 5-7 experiments are shown as the means \pm SEM. The two-vessel forebrain ischemia was induced by ligation of carotid arteries for $20 \mathrm{~min}$ and hypotension followed by reperfusion for $1 \mathrm{~h}$. Insulin was administered intranasally at a dose of $0.25 \mathrm{IU} /$ rat, while $\alpha$-T was given orally at a dose of $50 \mathrm{mg} / \mathrm{kg}$. *-The differences are significant according to Student's $t$-test as compared to control values in the brain cortex of sham-operated rats, $p<0.01$.

Thus, the combined use of insulin and $\alpha$-T prevented an increase in the levels of such LPO products as the conjugated dienes and trienes in brain of rats with ischemia/reperfusion. At the same time, the use of insulin or $\alpha$-T monotherapy was not effective. These data provide evidence that $\alpha$-T markedly increases the ability of insulin to normalize the metabolic disturbances in brain, which are induced by the activation of free radical reactions.

2.10. Additive Activating Effect of the Intranasally Administered Insulin and Orally Administered $\alpha-T$ on $\mathrm{Na}^{+}, \mathrm{K}^{+}$-ATPase Partially Inactivated in Brain Cortex of Rats with Two-Vessel Ischemia and Subsequent Reperfusion

We studied the ability of intranasally administered insulin $(0.25 \mathrm{IU} / \mathrm{rat})$ and of orally administered $\alpha$-T $(50 \mathrm{mg} / \mathrm{kg})$ to normalize the $\mathrm{Na}^{+}, \mathrm{K}^{+}$-ATPase activity which is markedly decreased in the brain cortex of rats with two-vessel forebrain ischemia and subsequent reperfusion. The $\mathrm{Na}^{+}, \mathrm{K}^{+}$-ATPase activity was found to be $24.6 \pm 1.27 \mu \mathrm{mol} \mathrm{P} \mathrm{i}_{\mathrm{i}} / \mathrm{mg}$ of protein $/ \mathrm{h}$ in control sham-operated rats, but it decreased (approximately by $35 \%$ ) to $15.95 \pm 0.82 \mu \mathrm{mol} \mathrm{P}_{\mathrm{i}} / \mathrm{mg}$ of protein $/ \mathrm{h}$ in ischemic and reperfused rats. Both insulin and $\alpha-$ $\mathrm{T}$ administration significantly increased the activity of $\mathrm{Na}^{+}, \mathrm{K}^{+}$-ATPase in the brain cortex of rats with brain ischemia and subsequent reperfusion, their effects were found to be additive. 
The most pronounced increase of enzyme activity to $23.1 \pm 0.83 \mu \mathrm{mol} \mathrm{P}_{\mathrm{i}} / \mathrm{mg}$ of protein $/ \mathrm{h}$ was reached if both protectors were administered to such rats (insulin intranasally and $\alpha$-T orally). The increase of the enzyme activity was in this case approximately equal to the sum of the increase caused by insulin and $\alpha$-T action (Table 2). Thus, when adding the effects of insulin and $\alpha$-T, acting separately, the increase in the $\mathrm{Na}^{+}, \mathrm{K}^{+}$-ATPase activity will be $7.9 \mu \mathrm{mol} \mathrm{P}_{\mathrm{i}} / \mathrm{mg}$ of protein $/ \mathrm{h}\left(2.55+5.35 \mu \mathrm{mol} \mathrm{P}_{\mathrm{i}} / \mathrm{mg}\right.$ of protein $\left./ \mathrm{h}\right)$. It is in a good agreement with the increase in enzyme activity obtained in experiments with coadministration of both drugs to rats with ischemic/reperfused forebrain injury $(7.15 \mu \mathrm{mol}$ $\mathrm{P}_{\mathrm{i}} / \mathrm{mg}$ of protein $/ \mathrm{h}$ ) (Table 2).

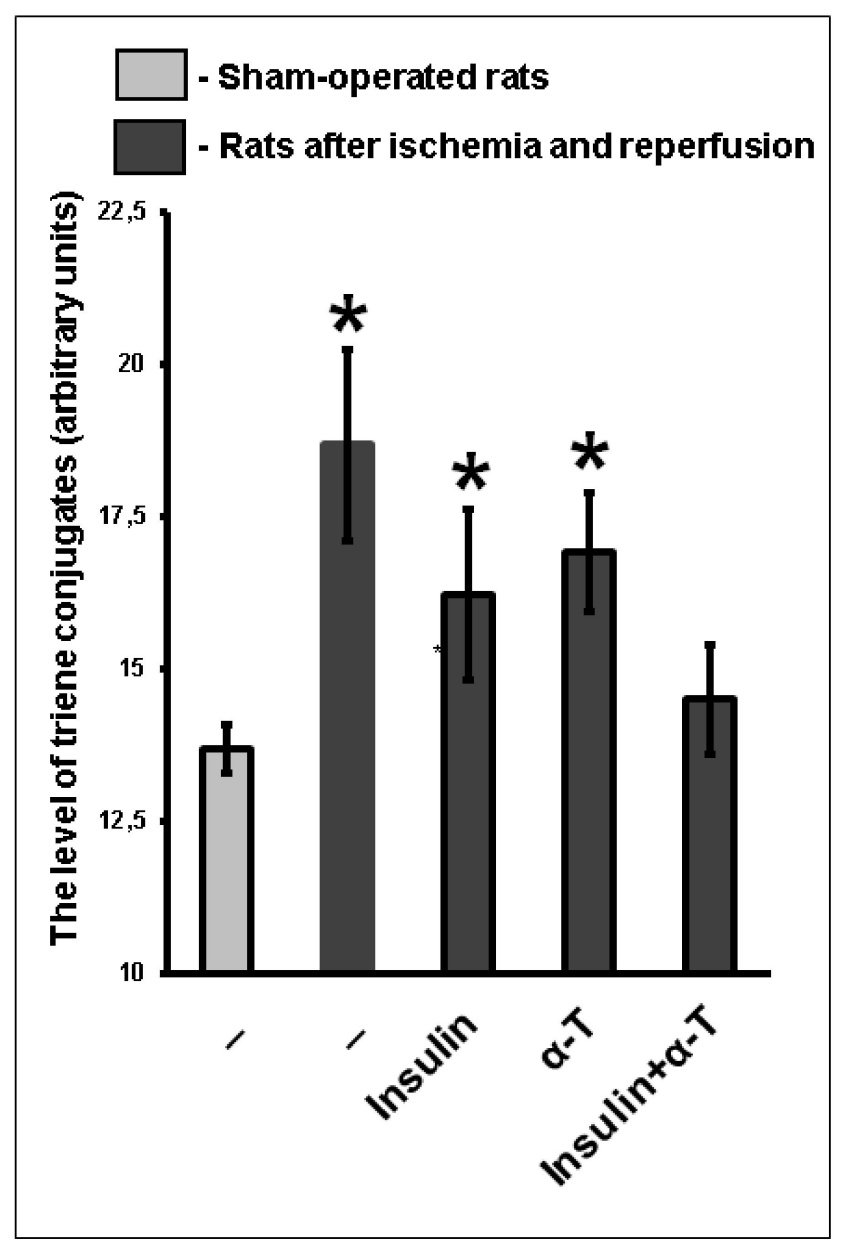

Figure 10. The effect of intranasally administered insulin and orally administered $\alpha$-T on the level of conjugated trienes in the brain cortex of rats with two-vessel forebrain ischemia followed by reperfusion. The data of 5-7 experiments are presented as the means \pm SEM. The two-vessel forebrain ischemia was induced by ligation of carotid arteries for $20 \mathrm{~min}$ and hypotension followed by reperfusion for $1 \mathrm{~h}$. Insulin was administered intranasally at a dose of $0.25 \mathrm{IU} / \mathrm{rat}$, while $\alpha$-T was given orally at a dose of $50 \mathrm{mg} / \mathrm{kg}$. *-The differences are significant according to Student's $t$-test as compared to control values in the brain cortex of sham-operated rats, $p<0.01$.

Then, by immunoblotting, the levels of $\alpha-2$ and $\alpha-3$ subunits of $\mathrm{Na}^{+}, \mathrm{K}^{+}$-ATPase in the cerebral cortex of ischemic and sham-operated rats and the effect of treatment with insulin and $\alpha-\mathrm{T}$ on it were investigated. It was shown that in ischemic rats the level of $\alpha-2$ and $\alpha-3$ subunits of $\mathrm{Na}^{+}, \mathrm{K}^{+}$-ATPase did not change (Supplementary Material Figures S1 and S2). Insulin, $\alpha-\mathrm{T}$ and their combination significantly increased the $\alpha-2$ subunit level in ischemic/reperfused rats (Supplementary Material Figure S1). In sham-operated rats, only $\alpha$-T increased the $\alpha-2$ subunit level (Supplementary Material Figure S1). In the case 
of the $\alpha-3$ subunit of $\mathrm{Na}^{+}, \mathrm{K}^{+}$-ATPase, administration of $\alpha$-T and both drugs significantly increased the level of this subunit in the cerebral cortex of both ischemic and sham-operated rats (Supplementary Material Figure S2).

Table 2. The effect of intranasally administered insulin and per-orally administered $\alpha-\mathrm{T}$ on $\mathrm{Na}^{+}, \mathrm{K}^{+}$-ATPase activity in brain cortex of rats with two-vessel ischemia followed by reperfusion $\left(\mu \mathrm{mol} \mathrm{P}_{\mathrm{i}} / \mathrm{mg}\right.$ of protein $\left./ \mathrm{h}\right)$.

\begin{tabular}{|c|c|c|}
\hline $\begin{array}{c}\text { Sham-Operated or Ischemic and } \\
\text { Reperfused Rats }\end{array}$ & Administration to Rats & $\begin{array}{c}\mathrm{Na}^{+}, \mathrm{K}^{+} \text {-ATPase Activity }\left(\mu \mathrm{mol} \mathrm{P}_{\mathrm{i}} / \mathrm{mg}\right. \\
\text { of Protein/h) }\end{array}$ \\
\hline Sham-operated rats & - & $24.6 \pm 1.27$ \\
\hline Sham-operated rats & $0.25 \mathrm{IU}$ insulin & $22.7 \pm 0.48$ \\
\hline Sham-operated rats & $50 \mathrm{mg} \alpha-\mathrm{T}$ per $\mathrm{kg}$ & $24.2 \pm 0.51$ \\
\hline Sham-operated rats & $0.25 \mathrm{IU}$ insulin and $50 \mathrm{mg} \alpha-\mathrm{T}$ per $\mathrm{kg}$ & $24.4 \pm 0.74$ \\
\hline Ischemic and reperfused rats & - & $15.95 \pm 0.82^{\mathrm{a}}$ \\
\hline Ischemic and reperfused rats & $0.25 \mathrm{IU}$ insulin & $18.5 \pm 0.82^{\mathrm{a}, \mathrm{b}}$ \\
\hline Ischemic and reperfused rats & $50 \mathrm{mg} \alpha$-T per kg & $21.3 \pm 0.83^{c}$ \\
\hline Ischemic and reperfused rats & $0.25 \mathrm{IU}$ insulin and $50 \mathrm{mg} \alpha-\mathrm{T}$ per $\mathrm{kg}$ & $23.1 \pm 0.83^{c, d}$ \\
\hline
\end{tabular}

The data of 6-8 experiments are given as the means \pm SEM. The two-vessel ischemia was induced by ligation of carotid arteries for 20 min and hypotension followed by reperfusion for $1 \mathrm{~h}$. Insulin was administered intranasally in a dose of $0.25 \mathrm{IU}$, while $\alpha$-T was given per-orally in a dose of $50 \mathrm{mg}$ per $\mathrm{kg}$ of rat body weight. The differences are significant according to Students' $t$-test as compared: ${ }^{\mathrm{a}}$-with control values in sham-operated rats, $p<0.01$, b,c with the effect of ischemia and reperfusion, ${ }^{\mathrm{b}} p<0.05,{ }^{\mathrm{c}} p<0.001$, ${ }^{\mathrm{d}}$ with the effect of insulin alone, $p<0.01$.

\section{Discussion}

A decrease of insulin content and insulin signaling in the brain is characteristic of Alzheimer's and Parkinson's diseases and diabetes mellitus. The deficit of insulin signaling leads to the impairment of metabolic processes in brain neurons and their function. It is one of the main causes of the disturbances in learning and memory. The most effective way of insulin delivery to the brain is its intranasal administration, in which insulin enters directly to the brain, bypassing the blood-brain barrier [11,12]. In clinical trials, the intranasal administration of insulin to patients with Alzheimer's and other neurodegenerative diseases was shown to improve the cognitive functions (see, for example, [15-19]). Meanwhile, in the course of these trials, the first evidence of the development of central insulin resistance appeared. The long-acting insulin analogue Detemir (21 days, $40 \mathrm{IU} /$ patient/day) significantly improved memory in patients with Alzheimer's disease and moderate cognitive deficits [15], but its improving effect with prolonged use (2-4 months) at the same daily dose disappeared [16]. These data suggest that long-acting insulin Detemir induces the chronic brain hyperinsulinemia, which leads to the insulin resistance of brain cells. Taking into account the possibility of the development of central insulin resistance as a result of prolonged intranasal administration of high-dose insulin, it is important to identify biologically active substances that can enhance the protective effect of insulin and increase its effectiveness at lower doses used for treatment. This can help to prevent a decrease in the insulin sensitivity of neurons with prolonged intranasal administration of this hormone to patients.

As far as the clinical trials of $\alpha$-T or vitamin $\mathrm{E}$ administration to patients are concerned, the data obtained are to a certain extent contradictory (see, for example, $[30,31,40]$ ). According to the data obtained by Dysken and co-authors [30], in the trials performed from 2007 to 2012, it was shown that prolonged (more than for two years) administration of vitamin E at a daily dose of $2000 \mathrm{IU}$ to patients with mild to moderate Alzheimer's disease resulted in slower decline in cognitive functions as compared to placebo group. $\alpha-T$ administration improved the activities of daily living and decreased the caregiver burden [30]. The treatment with $\alpha$-T of the patients with Alzheimer's disease having moderately severe impairment slowed the progression of the disease [40]. In this case, 
the clinical trials also took place for 2 years, and the patients received $2000 \mathrm{IU}$ of $\alpha$-T daily. At the same time, in this work the beneficial effect of $\alpha$-T administration for long time to patients with mild cognitive impairment was not revealed [40]. In the Cochrane Review of the clinical trials performed before 2000 year [31], no evidence was revealed that vitamin $\mathrm{E}$ or $\alpha$-T improved cognitive function in patients with mild cognitive impairment or dementia, characteristic to Alzheimer's disease. Meanwhile, the authors indicated that there was moderate quality evidence from a single study that $\alpha$-T administration could slow functional decline in patients with Alzheimer's disease. Vitamin E or $\alpha$-T was not associated with an increased risk of serious adverse events or mortality in various trials $[30,31,40]$. If patients with Alzheimer's disease received every day a mixture of folate, $\alpha$-T, vitamin B12, S-adenosyl methionine, $N$-acetylcysteine and acetyl-L-carnitine, it prevented the decline of their cognitive performance for a period over 12 months and improved the behavioral and psychological symptoms of dementia [41]. All these data suggest that $\alpha$-T treatment of humans appears to be safe and may have a positive effect on patients with neurodegenerative diseases.

We have shown that pre-incubation of brain cortex neurons in culture with $1 \mu \mathrm{M}$ insulin and $50 \mu \mathrm{M} \alpha$-T prior to application of hydrogen peroxide markedly increased the viability of these cells (Figure 1). The protective effect of the combination of these drugs was additive, it was significantly higher than the effect of each drug alone $(p<0.01)$. We used long (18 h) pre-incubation with $\alpha$-T, as in this case its neuroprotective effect is due to modulation of signaling pathways and not to its scavenging effect as in the case of short pre-incubation of neurons with this antioxidant [39,42]. $\alpha$-T was found to enhance the antiapoptotic effect of insulin as well (Figure 2).

Pre-incubation with either insulin or $\alpha$-T was found to decrease the formation of ROS in brain cortical neurons induced by hydrogen peroxide. The effect of insulin plus $\alpha$-T was more pronounced (Figure 3) than the effect of each of them, and the difference was significant $(p<0.05)$. Hydrogen peroxide-induced oxidative stress in brain cortical neuron resulted in the pronounced decrease in mitochondrial membrane potential. The pre-incubation of the neurons with insulin plus $\alpha$-T or with either insulin or $\alpha$-T alone led to the significant increase in $\Delta \psi(\mathrm{m})$, the effect of insulin plus $\alpha$-T being more pronounced (Figure 7) than the effect of each compound used separately $(p<0.01)$.

The enhancement of the protective effect of insulin by $\alpha$-T was not shown before our study. So, the mechanism of this effect is not known yet. In order to obtain the first data for understanding of this mechanism we studied the effect of insulin, $\alpha-T$ and their combination on the activity of Akt-kinase, GSK-3beta and ERK1/2. We estimated the ratio pAkt (Ser $\left.{ }^{473}\right) / A k t$ to show the activation of Akt. Insulin activated Akt-kinase both in control cortical neurons and in the neurons $15 \mathrm{~min}$ and $6 \mathrm{~h}$ after application of hydrogen peroxide (Figure 4). Meanwhile, we did not reveal the significant activating effect of $\alpha$-T on Akt at the same time points. In our previous studies we have found that not only insulin [43], but $\alpha$-T as well is able to activate Akt-kinase in brain cortical neurons under oxidative stress conditions [39], but the effect of these two drugs was detected at different time points after pro-oxidant addition $[39,43]$. In the present work it was shown that Akt activity in brain cortical neurons $6 \mathrm{~h}$ after the application of pro-oxidant is significantly higher in the case of application of insulin plus $\alpha$-T (Figure 4) as compared to application of insulin or $\alpha$-T alone ( $p<0.01$ by paired Student's $t$-test in both cases).

Activation of Akt has a protective effect as it increases the synthesis of the antiapoptotic protein $\mathrm{Bcl}-2$ and the ratio $\mathrm{Bcl}-2 / \mathrm{Bax}$, and inactivates kinase GSK-3beta, phosphorylating it at the $\operatorname{Ser}^{9}$ residue. The activation of GSK-3beta leads to the decrease in mitochondrial membrane potential, to the opening of mitochondrial permeability transition pores (mPTP) and to the increase in ROS formation in various cells, including neurons [44-46]. The inhibition of GSK-3beta improves the mitochondrial function. In the present study, we have shown that pre-incubation of brain cortical neurons with insulin significantly increased the phosphorylation of GSK-3beta at the $\mathrm{Ser}^{9}$ in control neurons and in the neurons $15 \mathrm{~min}$ and $6 \mathrm{~h}$ after the application of hydrogen peroxide to the cells (Figure 5). It means that insulin 
inactivated GSK-3beta. We have not revealed the effect of $\alpha$-T on the phosphorylation of GSK-3beta in control cells and $15 \mathrm{~min}$ after addition of prooxidant. At the same time in neurons $6 \mathrm{~h}$ after the application of hydrogen peroxide, the use of $\alpha$-T in the combination with insulin increased the phosphorylation of GSK-3beta and hence enhanced the insulininduced inactivation of this enzyme (Figure 5). The difference between the effect of insulin plus $\alpha$-T and the effects of each of them was significant $(p<0.01$ by paired Student's $t$-test). The ability of $\alpha$-T to enhance the Akt activation and GSK-3beta inactivation, induced by insulin, explains to a certain extent its ability to increase the protective effect of insulin on brain cortical neurons observed in our study.

The modulation of ERK1/2 activity by insulin and $\alpha$-T may also contribute to the ability of these drugs to enhance the protective effect of each other on the nerve cells. Previously, short activation of ERK1/2 by various compounds was shown to increase the viability of neurons [34-37], but long-term activation of ERK1/2 promoted nerve cells death [35,38]. In ischemic brain, the persistent activation of ERK1/2 occurs, and the ERK1/2 inhibitors were found to improve the brain metabolism and functional state of animals [47-50]. In the present study, we showed that in cultured brain cortical neurons, $6 \mathrm{~h}$ after the addition of hydrogen peroxide the ERK1/2 activity was increased. Pre-incubation of the neurons with insulin or $\alpha$-T decreased the activity of ERK1/2, and the combination of insulin and $\alpha$-T resulted in a more pronounced decrease in ERK1/2 activity, normalizing it in cortical neurons.

Thus, according to the data obtained in the present study, in brain cortical neurons, $\alpha-\mathrm{T}$ is able to increase the insulin-induced activation of Akt-kinase and to intensify the insulininduced inactivation of GSK-3beta and ERK1/2 at late stages of oxidative stress, thereby increasing the neuroprotective effects of insulin. Most probably, the ability of insulin and $\alpha$-T to increase the neuroprotective effects of each other depends on modulation of other signaling pathways and protein kinases as well, which requires further investigations.

One of the main causes of neuronal damage and death during brain ischemia and subsequent reperfusion is activation of free radical reactions. An important task was to find out whether insulin and $\alpha$-T are capable of enhancing each other's effects on metabolic abnormalities caused by the activation of free radical reactions, which are characteristic of two-vessel forebrain ischemia with hypotension and subsequent reperfusion.

It may be emphasized that in order to reveal the additive effect of insulin and $\alpha-\mathrm{T}$, we applied much lower doses of these drugs than are usually used when studying their protective effects in vivo. Effects of insulin administered intranasally to rats are usually studied using its dose of $0.5 \mathrm{IU} / \mathrm{rat}[51,52]$. As far as $\alpha$-T is concerned, administration of 125 or even $250 \mathrm{mg} / \mathrm{kg}$ of this compound to rats orally is used frequently when studying the protection elicited by a single or multiple administration of this drug [53,54]. In our experiments, we administered to rats once $0.25 \mathrm{IU}$ of insulin intranasally and twice $50 \mathrm{mg} / \mathrm{kg}$ of $\alpha$-T orally.

Levels of LPO products such as Schiff bases increased markedly in the brain cortex of rats with two-vessel forebrain ischemia/reperfusion injury. Both intranasal administration of insulin $(0.25 \mathrm{IU} / \mathrm{rat})$ and oral administration of $\alpha-\mathrm{T}(50 \mathrm{mg} / \mathrm{kg})$ to ischemic rats significantly diminished the accumulation of Schiff bases in the brain cortex. The most pronounced diminution of Schiff bases took place at co-administration of these drugs. In this case, the decrease of Schiff bases content was more pronounced as compared to administration of either insulin, or $\alpha$-T alone, the difference was significant $(p<0.01)$ (Figure 8).

The content of conjugated dienes and trienes also increased markedly in the brain cortex of rats subjected to two-vessel ischemia, hypotension and subsequent reperfusion. Neither intranasally administered insulin, nor orally administered $\alpha$-T could normalize the content of conjugated dienes or trienes in ischemic rats, as their level remained significantly higher as compared to their level in sham-operated rats. At the same time, co-administration of insulin and $\alpha$-T led to normalization of the levels of conjugated dienes and trienes in the brain cortex of rats with forebrain ischemia, they became practically 
equal to control values in the brain cortex of sham-operated rats, the difference was quite small and not significant (Figures 9 and 10). Thus, insulin and $\alpha$-T enhance the restoration effect of each other on brain metabolic processes under the conditions of activation of free radical reactions, and their combined use more effectively restored redox status of ischemic brain than monotherapy with these drugs.

The enzyme $\mathrm{Na}^{+}, \mathrm{K}^{+}$-ATPase is an important component of all animal cells, and its main function is the maintenance of resting potential of the cells and the regulation of cell volume. In the neurons, the difference in the concentrations of sodium and potassium ions in the cells and in the extracellular space, is a result of $\mathrm{Na}^{+}, \mathrm{K}^{+}$-ATPase activity and is used for propagation of the nerve impulses $[55,56]$. The decrease in the activity of $\mathrm{Na}^{+}, \mathrm{K}^{+}$-ATPase may be considered as an integral indicator of metabolic and functional impairments in the brain. The normalization of the activity of this enzyme may be an evidence of improvement of brain metabolism and functions. The decrease of $\mathrm{Na}^{+}, \mathrm{K}^{+}$-ATPase activity in ischemic and reperfused brain cortex may be a result of oxidative inactivation of this enzyme due to the decrease of the reduced SH groups and of the inhibitory effect of such LPO products as 4-hydroxynonenal [57-59]. The antioxidant effect of $\alpha$-T and insulin and their ability to reduce accumulation of LPO products contribute to their normalizing effect on $\mathrm{Na}^{+}, \mathrm{K}^{+}$-ATPase activity in the brain cortex of rats with two-vessel forebrain ischemia and subsequent reperfusion.

As we have shown, in the brain cortex of ischemic rats, the $\mathrm{Na}^{+}, \mathrm{K}^{+}$-ATPase activity was decreased significantly as compared to sham-operated rats, and the treatment with insulin or $\alpha$-T led to an increase in the enzyme activity ( $p<0.05$ and $p<0.01$, respectively). The co-administration of insulin and $\alpha$-T used at relatively low doses in the in vivo experiments appears to be effective, and their action was shown to be additive. These drugs enhance the ability of each other to reduce the ROS-induced metabolic disturbances and thereby prevent neurodegenerative processes in the ischemic and reperfused brain.

\section{Materials and Methods}

\subsection{Materials}

Poly-D-lysine, sodium dodecyl sulfate, 3-(4,5-dimethylthiazol-2-thiazolyl)-2,5-diphenyl2H-tetrazolium bromide (MTT), 2', $7^{\prime}$-dichlorofluorescein diacetate, hydrogen peroxide, $\mathrm{NADH}$ and insulin were obtained from Sigma-Aldrich (St. Louis, MO, USA). The neurobasal medium, B27 Supplement, B27 supplement without insulin, penicillin/streptomycin solution and glutamax were obtained from Gibco (Paisley, UK). Hanks buffered salt solution and trypsin/versen (1:1) solution were purchased from the Biolot Company (SaintPetersburg, Russia), and dimethylformamide was obtained from Vecton (Saint-Petersburg, Russia). The primary and secondary antibodies and other reagents used for immunoblotting are described in Section 4.6.

\subsection{Brain Cortical Neurons in Culture}

Immature brain cortical neurons were isolated from embryonic day 17-18 Wistar rat fetuses as previously described [60]. All procedures of using animals were performed in accordance with the European Community Council Directive 1986 (2010/63/EEC) and "Guide for the care and use of laboratory animals". They were approved by the Bioethics committee of the Institute of Evolutionary Physiology and Biochemistry of Russian Ac. Sci. In order to prepare primary cultures of immature brain cortical neurons the isolated cells were seeded on poly-D-lysine-coated 24-well and 12-well plates at a density of $5 \times 10^{5}$ and $1 \times 10^{6}$ cells per well, respectively. Cells were cultured in neurobasal medium containing $2 \%$ of B27 supplement, $2 \mathrm{mM}$ glutamax, $100 \mathrm{U} / \mathrm{mL}$ of penicillin and $100 \mu \mathrm{g} / \mathrm{mL}$ of streptomycin (growth medium). Every three days half of the culture medium was replaced. The beginning of the experiments took place on the 5 th-6th day in vitro of neuron cultivation in the growth medium. Before the start of the experimental work the growth medium was replaced by neurobasal medium containing 1\% B27 supplement without insulin, the neurons were left in it overnight. 
4.3. Determination of the Viability of Brain Cortical Neurons by MTT Method and of Activation of Caspoase-3 Measuring the Level of Its 17-19 kDa Fragment

Brain cortical neurons were preincubated with $50 \mu \mathrm{M} \alpha$-T for $18 \mathrm{~h}$ or with $1 \mu \mathrm{M}$ insulin for $1 \mathrm{~h}$ or with both protectors or without them in the neurobasal medium containing $1 \%$ B27 without insulin. Then the cells were exposed to $100 \mu \mathrm{M}$ hydrogen peroxide for $6 \mathrm{~h}$. The viability of brain cortical neurons in culture was evaluated by means of colorimetric 3-(4,5-dimethylthiazol-2-yl)-2,5-diphenyltetrazolium bromide (MTT) method. The MTT assay which is based on the ability of mitochondria of viable cells to reduce MTT to purplecolored MTT-formazan was conducted as previously described [61]. A microplate reader "Anthos" was used to measure the absorbance of MTT-formazan at $575 \mathrm{~nm}$. The extinction of the samples was expressed as percent of the extinction of control samples, which was taken for $100 \%$.

The caspase- 3 activity in brain cortical neurons and hence the apoptotic death of the cells was estimated measuring the level of cleaved caspase-3, that is the level of its $17-19 \mathrm{kDa}$ fragment in control neurons and in neurons $15 \mathrm{~min}$ and $6 \mathrm{~h}$ after the initiation of the oxidative stress in the cells by application of $100 \mu \mathrm{M}$ hydrogen peroxide. The level of this fragment shows the degree of cleavage and activation of caspase-3. It was measured using immunoblotting technique.

\subsection{Determination of ROS Formation in Brain Cortical Neurons}

Brain cortical neurons were preincubated with $50 \mu \mathrm{M} \alpha$-T for $18 \mathrm{~h}$ or with $1 \mu \mathrm{M}$ insulin for $1 \mathrm{~h}$ or with both protectors or without them in the neurobasal medium containing $1 \%$ of B27 Supplement without insulin. Then the cells were switched to Hanks' balanced salt solution (HBSS) to start loading of $10 \mu \mathrm{M}$ dye $2^{\prime}, 7^{\prime}$-dichlorofluorescein diacetate for $40 \mathrm{~min}$ at $37^{\circ} \mathrm{C}$ in the dark. After washing twice with HBSS, the neurons were exposed to $100 \mu \mathrm{M}$ hydrogen peroxide for $1 \mathrm{~h}$. The fluorescence of the reaction product of $2^{\prime}, 7^{\prime}$ dichlorofluorescein with ROS was determined using a Fluoroscan Ascent FL (Thermo Fisher Scientific, Helsinki, Finland) fluorimeter for plates (excitation at $\lambda=485 \mathrm{~nm}$, emission measured at $\lambda=538 \mathrm{~nm}$ ). The ROS levels in the samples were determined using arbitrary units.

4.5. Evaluation of Insulin, $\alpha$-T and Hydrogen Peroxide Effects on Akt, GSK-3beta and ERK1/2 Activities and Expression of These Protein Kinases and of Cleaved Caspase-3 Using Western Blot Analysis

After pre-incubation with $50 \mu \mathrm{M} \alpha$-T for $18 \mathrm{~h}$ or $1 \mu \mathrm{M}$ insulin for $1 \mathrm{~h}$ or with both protectors or without them hydrogen peroxide was added to the samples to the final concentration of $100 \mu \mathrm{M}$ for $6 \mathrm{~h}$. The cortical neurons were washed twice with ice-cold phosphate buffer solution (PBS). Then they were harvested in $60 \mu \mathrm{L}$ of lysis buffer. The lysis of cortical neurons and determination of protein concentrations were performed as previously described [39].

The equal amounts of lysates (20-25 $\mu$ g of protein) were loaded into each lane on $10 \%$ sodium dodecyl sulfate polyacrylamide gel. The electrophoresis of the samples was made at constant voltage. Afterwards, the proteins were transferred to $0.45 \mu \mathrm{m}$ Protran nitrocellulose membranes (Amersham, GE Healthcare, Little Chalfont, Buckinghamshire, UK). The nonspecific binding sites of the membranes were blocked as it was previously described [39]. Monoclonal antibodies specific for pAkt $\left(\operatorname{Ser}^{473}\right)(1: 1000$, \#4058, Cell Signaling Technology, Danvers, MA, USA), for pGSK-3beta (Ser $\left.{ }^{9}\right)$ (1:1000, \#9322, Cell Signaling Technology), for pERK1 (pThr ${ }^{202} / \mathrm{pTyr}^{204}$ ) and pERK2 (pThr $\left.{ }^{185} / \mathrm{pTyr}^{187}\right)$ (1:2000, \#E7028, Sigma-Aldrich), and for cleaved caspase-3 (Asp175) (1:1000, \#9664, Cell Signaling Technology) were used to probe the blots overnight at $+4{ }^{\circ} \mathrm{C}$. The specific antibodies to total Akt (1:1000, \#4691, Cell Signaling Technology), ERK1/2 (1:1000, \#9102, Cell Signaling Technology) and GSK-3beta (1:1000, \#9315, Cell Signaling Technology) were used to determine the level of these enzymes and the possible changes in their expression. After incubation with primary antibodies the blots were washed three times with $0.1 \%$ Tween 20 in Tris-buffered saline (50 mM Tris (pH 7,5), $150 \mathrm{mM} \mathrm{NaCl}$ ) and incubated with either anti-mouse (\#7076) or 
anti-rabbit (\#7074) HRP-IgG secondary antibody (Cell Signaling Technology) diluted in 5\% nonfat milk with TBST buffer for $1 \mathrm{~h}$ at room temperature. The ratios pAkt $\left(\mathrm{Ser}^{473}\right) / \mathrm{Akt}$, pERK1/2/Total ERK1/2, pGSK-3beta (Ser ${ }^{9}$ )/GSK-3beta were determined and taken as 1.0 in control cells. In order to normalize the data, membranes after stripping were re-probed for $\alpha$-tubulin (1:2000, \#T6074, Sigma-Aldrich). To check the changes of the expression of total ERK1/2, Akt and GSK-3beta, their ratio to $\alpha$-tubulin was determined and taken as 1.0 in control neurons. The stripping procedure was previously described [39]. The ratios of cleaved caspase-3 (17-19 kDa fragment) / $\alpha$-tubulin were also determined. These ratio in control cells was taken as 1.00. Blots were developed with an Novex ECL HRP enhanced chemiluminescence detection reagent Kit (Invitrogen, Waltham, MA, USA). The films were scanned on a CanoScan 8800F scanner (Canon, Tokyo, Japan). Bio7 was used to quantify the optical densities of the positive bands.

4.6. Determination of the Effects of Hydrogen Peroxide Application and of Pre-Incubation with Insulin and $\alpha$-Tocopherol on Mitochondrial Membrane Potentials in Brain Cortical Neurons in Culture

Evaluation of mitochondrial membrane potentials $(\Delta \psi(\mathrm{m}))$ in brain cortical neurons was performed by the flow cytometry method using the fluorescent dye tetramethylrhodamine (TMRM) [62]. Prior to the beginning of the experiments the growth medium was changed to neurobasal medium containing $1 \%$ of B27 supplement without insulin and brain cortical neurons were incubated in it for $6 \mathrm{~h}$. Then the neurons were pre-incubated with insulin and/or $\alpha$-T for $20 \mathrm{~h}$ in this medium, afterward hydrogen peroxide was added to the samples to the final concentration of $100 \mu \mathrm{M}$ and the neurons were incubated for $1 \mathrm{~h}$. The cells were taken off the wells by trypsin-versen (1:1) and washed by HBSS. The residue was resuspended in HBSS containing $100 \mathrm{nM}$ TMRM. Then the incubation with it for 30-40 min at $37^{\circ} \mathrm{C}$ in the dark was performed. The samples were analyzed by flow-cytometry method using an Epics XL cytometer (Beckman Coulter, Brea, CA, USA. Fluorescence was measured at $575 \mathrm{~nm}$ in an F2 channel. At least 10,000 events were recorded in each sample. The intensity of fluorescence was shown on logarithmic scale, it was expressed in arbitrary units as the mean intensity of fluorescence. The program WinMDI, version 2.9 was used in order to analyze the cytofluorometric data.

\subsection{Two-Vessel Forebrain Ischemia in Wistar Rats}

The experiments were performed using Wistar rats kept in standard vivarium conditions and weighing 270-330 g. All procedures of using animals were performed in accordance with the European Community Council Directive 1986 (2010/63/EEC) and "Guide for the care and use of laboratory animals". They were approved by the Bioethics committee of the Institute of Evolutionary Physiology and Biochemistry of Russian Ac. Sci. Chloral hydrate ( $400 \mathrm{mg} / \mathrm{kg}$ body weight) was used for anesthesia. Two-vessel forebrain ischemia was induced by 20-min occlusion of carotid arteries in combination with hypotension. Hypotension was induced by blood sampling until reaching arterial pressure of $50 \mathrm{~mm} \mathrm{Hg}$ as it was described previously [63]. Before blood sampling rats were injected with $0.2 \mathrm{~mL} 0.9 \% \mathrm{NaCl}$ containing $10 \mathrm{IU}$ of heparin, then blood was taken in the same syringe. Upon cessation of 20-min occlusion, the carotid arteries were unclamped and heparinized blood withdrawn at the ischemic stage was returned back to the cerebral circulation. The brain was reperfused for $1 \mathrm{~h}$. The data obtained for sham-operated rats were used as controls. Intranasal administration of insulin was performed $1 \mathrm{~h}$ before occlusion of carotid arteries by putting $10 \mu \mathrm{L}$ of citrate buffer solution containing insulin into each nostril. Citrate buffer was prepared from equal volumes of $100 \mathrm{mM}$ citric acid and $100 \mathrm{mM}$ sodium citrate, $\mathrm{pH}$ 4.4. The solution of citrate buffer contained $0.5 \mathrm{mg}$ insulin in $1 \mathrm{~mL}$. It corresponds to insulin dose of $0.25 \mathrm{IU}$ in $20 \mu \mathrm{L}$ of the solution, which was administered to rats intranasally in our experiments. $\alpha$-T was given to rats per-orally $(50 \mathrm{mg}$ per $\mathrm{kg}$ of rat body weight in the evening a day before operation and $1 \mathrm{~h}$ before the beginning of operation. 
4.8. Determination of Lipid Peroxidation Products, $\mathrm{Na}^{+}, \mathrm{K}^{+}$-ATPase Activity and $\mathrm{Na}^{+}, \mathrm{K}^{+}$-ATPase subunits expression in Brain Cortex of Rats after Two-Vessel Ischemia and Reperfusion

Upon cessation of reperfusion, animals were decapitated, with the brain cortex withdrawn thereafter. The level of various lipid peroxidation products was studied in lipid extracts of the rat brain cortex. Lipids were extracted with chloroform-methanol (2:1), as previously described [64]. In order to get rid from nonlipid admixtures the extracts were washed with cooled $0.9 \% \mathrm{NaCl}$ solution in water $(0.2$ volumes of the lipid extract $)$ as recommended by Folch and co-authors. Then the surface of the lower phase was washed twice with a "theoretical upper layer"-chloroform:methanol: $\mathrm{H}_{2} \mathrm{O}$ mixture (3:48:47). Then the lipid extract was evaporated and dissolved in chloroform. The fluorescent intensity of Schiff bases was measured on a RF 1501 spectrofluorometer (Shimadzu, Kyoto, Japan) (excitation at $\lambda=370 \mathrm{~nm}$, emission measured at $\lambda=450 \mathrm{~nm}$ [65]. The results were expressed as relative units (fluorescence units) per $1 \mathrm{mg}$ of lipids. To determine the level of conjugated diene and triene, the evaporated lipid extract was dissolved in a mixture of methanol and hexane (5:1). Ultraviolet absorbance, measured at 232 and $274 \mathrm{~nm}$, was employed to monitor the formation of conjugated dienes and trienes, respectively, and the measurement was performed on spectrophotometer UV-2401 (Shimadzu). The increasing absorption values are an indication that lipid peroxidation is proceeding [66]. The content of conjugated dienes and trienes was expressed in arbitrary units per $1 \mathrm{mg}$ of lipids.

$\mathrm{Na}^{+}, \mathrm{K}^{+}$-ATPase activity was determined in the crude synaptosome fraction $\left(\mathrm{P}_{2-}\right.$ fraction) from the rat brain cortex by a coupled reaction in the presence of excess pyruvate kinase, lactate dehydrogenase and phosphoenolpyruvate as reported previously [67]. $\mathrm{Na}^{+}, \mathrm{K}^{+}$-ATPase activity was expressed in $\mu$ moles of inorganic phosphate $\left(\mathrm{P}_{\mathrm{i}}\right)$ per $1 \mathrm{mg}$ protein for $1 \mathrm{~h}$.

The level of $\alpha-2$ and $\alpha-3$ subunit of $\mathrm{Na}^{+}, \mathrm{K}^{+}$-ATPase in the rat brain cortex was measured by means of Western blot analysis. The dissected brain cortex tissues were homogenized in the ratio 1:20 in the lysis buffer. This buffer contained $20 \mathrm{mM}$ Tris- $\mathrm{HCl}(\mathrm{pH} 7.5)$, $150 \mathrm{mM} \mathrm{NaCl}, 2 \mathrm{mM}$ EGTA, 2 mM EDTA, 0.5\% sodium deoxycholate, 0.5\% Triton X-100, $15 \mathrm{mM} \mathrm{NaF}, 10 \mathrm{mM}$ sodium glycerophosphate, $10 \mathrm{mM}$ sodium pyrophosphate, $1 \mathrm{mM}$ $\mathrm{Na}_{3} \mathrm{VO}_{4}, 1 \mathrm{mM}$ phenylmethylsulfonyl fluoride (PMSF), $0.02 \% \mathrm{NaN}_{3}$, and the protease inhibitor cocktail (Roche, Switzerland). The cell fragments and the undamaged cells were separated by centrifugation at $500 \times g$ for $10 \mathrm{~min}\left(4^{\circ} \mathrm{C}\right)$. The protein concentration was measured by the Lowry method with BSA as a standard. Twenty micrograms of protein per sample were run on 9\% SDS-polyacrylamide gel. Specific antibodies raised against Sodium Pump subunit $\alpha$-2 (1:1000, \#LS-C368564, LifeSpan BioSciences Inc., Seattle, WA, USA) and Sodium Potassium ATPase $\alpha 3$ subunit (1:1000, \#NB300-540, Novus Biologicals, Centennial, CO, USA) were applied for immunostaining in Western Blot Analysis. To normalize the data, the membranes were treated with the antibodies against glyceraldehyde 3-phosphate dehydrogenase (GAPDH) (1:5000, \#NB600-502, Novus Biologicals).

\subsection{Statistical Analysis}

Data are presented as mean \pm SEM. The statistical significance of the differences between three or more groups of data was assessed by one-way analysis of variance (ANOVA) followed by Tukey's test for multiple comparisons. Statistical significance of differences between two groups of data was determined using the Student's $t$-test or Student's paired $t$-test. Student's paired $t$ test was used in the case of immunoblotting experiments performed on primary cultures of brain cortex neurons. Differences were considered significant at $p<0.05$.

\section{Conclusions}

Clinical trials show that insulin administered intranasally is promising as a drug for neurodegenerative and, probably. other diseases associated with brain damage. However, long-term systemic or intranasal administration of high-dose insulin can lead to insulin resistance, including the brain insulin resistance. It seems of importance to reveal endoge- 
nous or exogenous substances that can enhance the neuroprotective effect of insulin, and these substances may include $\alpha$-T, the main and most active component of vitamin $\mathrm{E}$. The aim of our work was to study the effectiveness of the insulin plus $\alpha$-T combination to prevent the death of cultured brain cortical neurons under conditions of oxidative stress and to normalize ROS-induced metabolic dysfunctions in the cerebral cortex of rats with two-vessel forebrain ischemia/reperfusion injury.

In our study, it was for the first time shown that $\alpha$-T significantly enhanced the protective, antiapoptotic, and antioxidative effects of insulin on cortical neurons under conditions of oxidative stress. The protective and antioxidative effects of these drugs were additive. Pre-incubation of neurons with $1 \mu \mathrm{M}$ insulin plus $50 \mu \mathrm{M} \alpha$-T increased the viability of brain cortical neurons more than pre-incubation with either of these drugs. The pronounced increase of cleaved caspase-3 level (17-19 kDa) and hence of caspase-3 activation was observed $6 \mathrm{~h}$ after the beginning of the exposure of neurons to $100 \mu \mathrm{M}$ hydrogen peroxide. The combined use of insulin and $\alpha$-T decreased the level of cleaved caspase-3 (and, consequently, the apoptotic death of neurons) to a greater extent than pre-incubation with each of these drugs. In cortical neurons, the antioxidant effect of insulin plus $\alpha-\mathrm{T}$ was more pronounced than in the case of the application of insulin or $\alpha$-T alone.

As the enhancement of neuroprotective effect of insulin by $\alpha$-T was first shown in our study, the mechanisms of this effect were not known. In order to decipher them, we studied the modulation of the activity of various protein kinases by insulin, $\alpha$-T and insulin plus $\alpha$-T in cultured brain cortical neurons under conditions of oxidative stress, induced by hydrogen peroxide. At the later stages of oxidative stress, the combined action of insulin and $\alpha-T$ led to an increase in Akt activity, inactivation of GSK 3beta and normalization of ERK1/2 activity, and these effects were more pronounced than those of either drug.

In rats, forebrain ischemia and subsequent reperfusion increased the content of LPO products and caused oxidative inactivation of $\mathrm{Na}^{+}, \mathrm{K}^{+}$-ATPase in the cerebral cortex. Coadministration of insulin and $\alpha-\mathrm{T}$ resulted in a more pronounced normalization of the levels of Schiff bases, conjugated dienes and trienes and the activity of $\mathrm{Na}^{+}, \mathrm{K}^{+}$-ATPase than the administration of one of these drugs. As activation of free radical reactions is one of the main causes of nerve cell damage and death in the ischemic and reperfused brain, these data suggest that $\alpha$-T is able to enhance the neuroprotective effect of insulin in ischemic conditions followed by reperfusion. Further experiments will show whether the combined use of insulin and $\alpha-\mathrm{T}$ is able to prevent effectively neuropathies characteristic of neurodegenerative, ischemic and other brain injuries.

Supplementary Materials: The following are available online at https:/ /www.mdpi.com/article/10 $.3390 /$ ijms222111768/s1.

Author Contributions: Conceptualization: N.F.A., A.O.S. and I.O.Z.; Methodology: I.O.Z., L.V.B., I.I.Z., T.V.S. and N.F.A.; Validation: L.V.B.; Investigation: I.O.Z., L.V.B., I.I.Z. and T.V.S.; Writing: N.F.A. and A.O.S.; Visualization: I.I.Z. and L.V.B.; Funding Acquisition: A.O.S. All authors have read and agreed to the published version of the manuscript.

Funding: This work was supported by funds from the Ministry of Science and Higher Education of Russian Federation (agreement No. 075-1502020-916 of 16 November 2020 on the provision of a grant in the form of subsidies from the federal budget for the implementation of state support for the creation and development of the "Pavlovsky Center" National Center for Medical Education).

Institutional Review Board Statement: Research with the participation of animals is in accordance with the principles of international ethics, protocol \#11/2020 of the Bioethics Committee of Institute of Evolutionary Physiology and Biochemistry of Russian Ac. Sci, session 11 of 28 November 2020, because all laboratory animals (rats too) are animals.

Data Availability Statement: Data is contained within the article or supplementary material.

Conflicts of Interest: The authors declare no conflict of interest. 


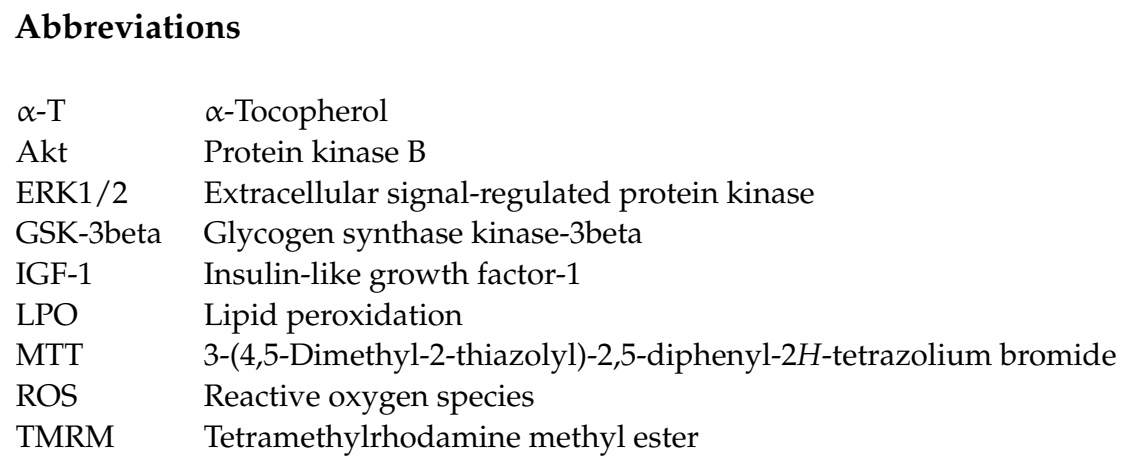

\section{References}

1. Fine, J.M.; Stroebel, B.M.; Faltesek, K.A.; Terai, K.; Haase, L.; Knutzen, K.E.; Kosyakovsky, J.; Bowe, T.J.; Fuller, A.K.; Frey, W.H.; et al. Intranasal delivery of low-dose insulin ameliorates motor dysfunction and dopaminergic cell death in a 6-OHDA rat model of Parkinson's Disease. Neurosci. Lett. 2020, 714, 134567. [CrossRef]

2. Hendrickx, J.O.; Moudt, S.; Calus, E.; Martinet, W.; Pieter-Jan, D.F.; Guns, P.-J.D.F.; Roth, L.; Peter, P.; De Deyn, P.P.; Van Dam, D.; et al. Serum corticosterone and insulin resistance as early biomarkers in the hAPP23 overexpressing mouse model of Alzheimer's disease. Int. J. Mol. Sci. 2021, 22, 6656. [CrossRef]

3. Toljan, K.; Homolak, J. Circadian changes in Alzheimer's disease: Neurobiology, clinical problems, and therapeutic opportunities. Handb. Clin. Neurol. 2021, 179, 285-300. [CrossRef]

4. Chua, L.-M.; Lim, M.-L.; Chong, P.-R.; Hu, Z.P.; Cheung, N.S.; Wong, B.S. Impaired neuronal insulin signaling precedes A $\beta 42$ accumulation in female A $\beta P$ sw /PS1 $\triangle E 9$ mice. J. Alzheimers Dis. 2012, 29, 783-791. [CrossRef] [PubMed]

5. Chen, Y.; Zhao, Y.; Dai, C.-L.; Liang, Z.; Run, X.; Iqbal, K.; Liu, F.; Gong, C.-X. Intranasal insulin restores insulin signaling, increases synaptic proteins, and reduces A $\beta$ level and microglia activation in the brains of 3xTg-AD mice. Exp. Neurol. 2014, 261, 610-619. [CrossRef]

6. Rajasekar, N.; Hanif, K.; Shukla, R. Intranasal insulin improves cerebral blood flow, Nrf-2 expression and BDNF in STZ (ICV)-induced memory impaired rats. Life Sci. 2017, 173, 1-10. [CrossRef] [PubMed]

7. Erichsen, J.M.; Calva, C.B.; Reagan, L.P.; Fadel, J.R. Intranasal insulin and orexins to treat age-related cognitive decline. Physiol. Behav. 2021, 234, 113370. [CrossRef]

8. Minokoshi, Y.; Alquier, T.; Furukawa, N.; Kim, Y.B.; Lee, A.; Xue, B.; Mu, J.; Foufelle, F.; Ferre, P.; Birnbaum, M.J.; et al. AMP-kinase regulates food intake by responding to hormonal and nutrient signals in the hypothalamus. Nature 2004, 428, 569-574. [CrossRef] [PubMed]

9. Derkach, K.V.; Bogush, I.V.; Berstein, L.M.; Shpakov, A.O. The influence of intranasal insulin on hypothalamic-pituitary axis in normal and diabetic rats. Horm. Metab. Res. 2015, 47, 916-924. [CrossRef]

10. Inoue, H. Central insulin-mediated regulation of hepatic glucose production. Endocr. J. 2016, 63, 1-7. [CrossRef]

11. Fan, L.W.; Carter, K.; Bhatt, A.; Pang, Y. Rapid transport of insulin to the brain following intranasal administration in rats. Neural Regen. Res. 2019, 14, 1046-1051. [CrossRef]

12. Tashima, T. Shortcut approaches to substance delivery into the brain based on intranasal administration using nanodelivery strategies for insulin. Molecules 2020, 25, 5188. [CrossRef]

13. Chen, Y.; Guo, Z.; Mao, Y.F.; Zheng, T.; Zhang, B. Intranasal insulin ameliorates cerebral hypometabolism, neuronal loss, and astrogliosis in streptosotocin-induced Alzheimer's rat model. Neurotox. Res. 2018, 33, 716-724. [CrossRef]

14. Lv, H.; Tang, L.; Guo, C.; Jiang, Y.; Gao, C.; Wang, Y.; Jian, C. Intranasal insulin administration may be highly effective in improving cognitive function in mice with cognitive dysfunction by reversing brain insulin resistance. Cogn. Neurodyn. 2020, 14, 323-338. [CrossRef]

15. Claxton, A.; Baker, L.D.; Hanson, A.J.; Trittschuh, E.H.; Collerton, B.; Morgan, A.; Callaghan, M.; Arbuckle, M.; Behl, C.; Craft, S. Long-acting intranasal insulin detemir improves cognition for adults with mild cognitive impairment or early-stage Alzheimer's disease dementia. J. Alzheimers Dis. 2015, 44, 897-906. [CrossRef]

16. Craft, S.; Claxton, A.; Baker, L.D.; Hanson, A.J.; Collerton, B.; Trittschuh, E.H.; Dahl, D.; Caulder, E.; Neth, B.; Montine, T.J.; et al. Effects of regular and long-acting insulin on cognition and Alzheimer's disease biomarkers: A pilot clinical trial. J. Alzheimers Dis. 2017, 57, 1325-1334. [CrossRef]

17. Avgerinos, K.I.; Kalaitzidis, G.; Malli, A.; Kalaitzoglou, D.; Myserlis, P.G.; Lioutas, V.-A. Intranasal insulin in Alzheimer's dementia or mild cognitive impairment. A systematic review. J. Neurol. 2018, 265, 1497-1510. [CrossRef]

18. Miziak, B.; Błaszczyk, B.; Czuczwar, S.J. Some candidate drugs for pharmacotherapy of Alzheimer's disease. Pharmaceuticals 2021, 14, 458. [CrossRef]

19. Hallschmid, M. Intranasal insulin. J. Neuroendocrinol. 2021, 33, e12934. [CrossRef]

20. Novak, P.; Maldonado, D.A.P.; Novak, V. Safety and preliminary efficacy of intranasal insulin for cognitive impairment in Parkinson disease and multiple system atrophy: A double-blinded placebo-controlled pilot study. PLoS ONE 2019, 14, e0214364. [CrossRef] 
21. Zorina, I.I.; Zakharova, I.O.; Bayunova, L.V.; Avrova, N.F. Insulin administration prevents accumulation of conjugated dienes and trienes and inactivation of $\mathrm{Na}^{+}, \mathrm{K}^{+}$-ATPase in the rat cerebral cortex during two-vessel forebrain ischemia and reperfusion. J. Evol. Biochem. Physiol. 2018, 54, 246-249. [CrossRef]

22. Zorina, I.I.; Fokina, E.A.; Zakharova, I.O.; Bayunova, L.V.; Shpakov, A.O. Characteristics of changes in lipid peroxidation and $\mathrm{Na}^{+} / \mathrm{K}^{+}$-ATPase activity in the cortex of old rats in conditions of two-vessel cerebral ischemia/reperfusion. Adv. Geront. 2020, 10, 156-161. [CrossRef]

23. Russo, V.; Candeloro, P.; Malara, N.; Perozziello, G.; Iannone, M.; Scicchitano, M.; Mollace, R.; Musolino, V.; Gliozzi, M.; Carresi, C.; et al. Key role of cytochrome $\mathrm{C}$ for apoptosis detection using Raman microimaging in an animal model of brain ischemia with insulin treatment. Appl. Spectrosc. 2019, 73, 1208-1217. [CrossRef]

24. Huang, S.S.; Lu, Y.J.; Huang, J.P.; Wu, Y.T.; Day, Y.J.; Hung, L.M.J. The essential role of endothelial nitric oxide synthase activation in insulin-mediated neuroprotection against ischemic stroke in diabetes. Vasc. Surg. 2014, 59, 483-491. [CrossRef]

25. Rizk, N.N.; Rafols, J.A.; Dunbar, J.C. Cerebral ischemia-induced apoptosis and necrosis in normal and diabetic rats: Effects of insulin and C-peptide. Brain Res. 2006, 1096, 204-212. [CrossRef]

26. Liu, X.F.; Fawcett, J.R.; Thorne, R.G.; DeFor, T.A.; Frey, W.H., 2nd. Intranasal administration of insulin-like growth factor-I bypasses the blood-brain barrier and protects against focal cerebral ischemic damage. J. Neurol. Sci. 2001, 187, 91-97. [CrossRef]

27. Lin, S.; Rhodes, P.G.; Cai, Z. Whole body hypothermia broadens the therapeutic window of intranasally administered IGF-1 in a neonatal rat model of cerebral hypoxia-ischemia. Brain Res. 2011, 1385, 246-256. [CrossRef]

28. Shen, H.; Gu, X.; Wei, Z.Z.; Wu, A.; Liu, X. Combinatorial intranasal delivery of bone marrow mesenchymal stem cells and insulin-like growth factor-1 improves neurovascularization and functional outcomes following focal cerebral ischemia in mice. Exp. Neurol. 2021, 337, 113542. [CrossRef]

29. Lioutas, V.A.; Alfaro-Martinez, F.; Bedoya, F.; Chung, C.C.; Pimentel, D.A.; Novak, V. Intranasal insulin and insulin-like growth factor-1 as neuroprotectants in acute ischemic stroke. Transl. Stroke Res. 2015, 6, 264-275. [CrossRef]

30. Dysken, M.W.; Sano, M.; Asthana, S.; Vertrees, J.E.; Pallaki, M.; Llorente, M.; Love, S.; Schellenberg, G.D. Effect of vitamin $\mathrm{E}$ and memantine on functional decline in Alzheimer's disease: The TEAM-AD VA cooperative randomized trial. JAMA 2014, 311, 33-44. [CrossRef]

31. Farina, N.; Llewellyn, D.; Nasr, I.M.G.K.; Tabet, N. Vitamin E for Alzheimer's dementia and mild cognitive impairment. Cochrane Database Syst. Rev. 2017, 4, CD002854. [CrossRef]

32. Wei, Z.; Koya, J.; Reznik, S.E. Insulin resistance exacerbates Alzheimer disease via multiple mechanisms (mini-review). Front. Neurosci. 2021. [CrossRef]

33. Ashley, S.; Bradburn, S.; Murgatroyd, C. A meta-analysis of peripheral tocopherol levels in age-related cognitive decline and Alzheimer's disease. Nutr. Neurosci. 2019, 1-15. [CrossRef] [PubMed]

34. Ziegler, C.G.; Sicard, F.; Sperber, S.; Ehrhart-Bornstein, M.; Bornstein, S.R.; Krug, A.W. DHEA reduces NGF-mediated cell survival in serum-deprived PC12 cells. Ann. N. Y. Acad. Sci. 2006, 1073, 306-311. [CrossRef]

35. Vauzour, D.; Vafeiadou, K.; Rice-Evans, C.; Williams, R.J.; Spencer, J.P. Activation of pro-survival Akt and ERK1/2 signalling pathways underlie the anti-apoptotic effects of flavanones in cortical neurons. J. Neurochem. 2007, 103, 1355-1367. [CrossRef] [PubMed]

36. Luo, Y.; DeFranco, D.B. Opposing roles for ERK $1 / 2$ in neuronal oxidative toxicity: Distinct mechanisms of ERK $1 / 2$ action at early versus late phases of oxidative stress. J. Biol. Chem. 2006, 281, 16436-16442. [CrossRef]

37. Cao, Q.; Qin, L.; Huang, F.; Wang, X.; Yang, L.; Shi, H.; Wu, H.; Zhang, B.; Chen, Z.; Wu, X. Amentoflavone protects dopaminergic neurons in MPTP-induced Parkinson's disease model mice through PI3K/Akt and ERK signaling pathways. Toxicol. Appl. Pharmacol. 2017, 319, 80-90. [CrossRef]

38. Ho, Y.; Samarasinghe, R.; Knoch, M.E.; Lewis, M.E.; Aizenman, E.; DeFranco, D.B. Selective inhibition of mitogen-activated protein kinase phosphatases by zinc accounts for extracellar signal-regulated kinase 1/2-dependent oxidative neuronal cell death. Mol. Pharmacol. 2008, 74, 1141-1151. [CrossRef]

39. Zakharova, I.O.; Sokolova, T.V.; Vlasova, Y.A.; Bayunova, L.V.; Rychkova, M.P.; Avrova, N.F. $\alpha$-Tocopherol at nanomolar concentration protects cortical neurons against oxidative stress. Int. J. Mol. Sci. 2017, 18, 216. [CrossRef] [PubMed]

40. Sano, M.; Ernesto, C.; Thomas, R.G.; Klauber, M.R.; Schafer, K.; Grundman, M.; Woodbury, P.; Growdon, J.; Cotman, C.W.; Pfeiffer, E.; et al. A controlled trial of selegiline, alpha-tocopherol, or both as treatment for Alzheimer's disease: The Alzheimer's disease cooperative study. N. Engl. J. Med. 1997, 336, 1216-1222. [CrossRef] [PubMed]

41. Remington, R.; Bechtel, C.; Larsen, D.; Samar, A.; Page, R.; Morrel, C.; Shea, T.B. Maintenance of cognitive performance and mood for individuals with Alzheimer's disease following consumption of a nutraceutical formulation: A one-year, open-label study. J. Alzheimers Dis. 2016, 51, 991-995. [CrossRef]

42. Zakharova, I.O.; Sokolova, T.V.; Bayunova, L.V.; Vlasova, Y.A.; Rychkova, M.P.; Avrova, N.F. $\alpha$-Tocopherol at nanomolar concentration protects PC12 cells from hydrogen peroxide-induced death and modulates protein kinase activities. Int. J. Mol. Sci. 2012, 13, 11543-11568. [CrossRef]

43. Zakharova, I.O.; Sokolova, T.V.; Bayunova, L.V.; Zorina, I.I.; Rychkova, M.P.; Shpakov, A.O.; Avrova, N.F. The protective effect of insulin on rat cortical neurons in oxidative Stress and its dependence on the modulation of Akt, GSK-3beta, ERK1/2, and AMPK activities. Int. J. Mol. Sci. 2019, 20, 3702. [CrossRef] 
44. Vélez, D.E.; Mestre-Cordero, V.E.; Hermann, R.; Perego, J.; Harriet, S.; Fernandez-Pazos, M.L.M.; Mourglia, J.; Marina-Prendes, M.G. Rosuvastatin protects isolated hearts against ischemia-reperfusion injury: Role of Akt-GSK-3beta, metabolic environment, and mitochondrial permeability transition pore. J. Physiol. Biochem. 2020, 76, 85-98. [CrossRef] [PubMed]

45. Wang, X.; Sun, Q.; Jiang, Q.; Jiang, Y.; Zhang, Y.; Cao, J.; Lu, L.; Li, C.; Wei, P.; Wang, Q.; et al. Cryptotanshinone Ameliorates Doxorubicin-Induced Cardiotoxicity by Targeting Akt-GSK-3 $\beta$-mPTP Pathway In Vitro. Molecules 2021, 26, 1460. [CrossRef] [PubMed]

46. Luo, P.; He, W.X.; Li, C.; Chang, M.J. Enteric glial cells exert neuroprotection from hyperglycemia-induced damage via Akt/GSK3 $\beta$ pathway. Neuroreport 2021, 32, 875-881. [CrossRef] [PubMed]

47. Namura, S.; Iihara, K.; Takami, S.; Nagata, I.; Kikuchi, H.; Matsushita, K.; Moskowitz, M.A.; Bonventre, J.V.; Alessandrini, A. Intravenous administration of MEK inhibitor UO126 affords brain protection against forebrain ischemia and focal cerebral ischemia. Proc. Natl. Acad. Sci. USA 2001, 98, 11569-11574. [CrossRef] [PubMed]

48. Chu, C.T.; Levinthal, D.J.; Kulich, S.M.; Chalovich, E.M.; DeFranco, D.B. Oxidative neuronal injury. The dark side of ERK1/2. Eur. J. Biochem. 2004, 271, 2060-2066. [CrossRef]

49. Lu, K.; Liang, C.L.; Liliang, P.C.; Yang, S.-H.; Cho, C.L.; Weng, H.C.; Tsai, Y.-D.; Wang, K.W.; Chen, H.J. Inhibition of extracellular signal-regulated kinases $1 / 2$ provides neuroprotection in spinal cord ischemia/reperfusion injury in rats: Relationship with the nuclear factor-kB-regulated anti-apoptotic mechanisms. J. Neurochem. 2010, 114, 237-246. [CrossRef] [PubMed]

50. Wang, W.Y.; Xie, L.; Zou, X.S.; Li, N.; Yang, Y.G.; Wu, Z.J.; Tian, X.Y.; Zhao, G.Y.; Chen, M.H. Inhibition of extracellular signalregulated kinase/calpain-2 pathway reduces neuroinflammation and necroptosis after cerebral ischemia-reperfusion injury in a rat model of cardiac arrest. Int. Immunopharmacol. 2021, 93, 107377. [CrossRef]

51. Derkach, K.V.; Ivantsov, A.O.; Chistyakova, O.V.; Sukhov, I.B.; Buzanakov, D.M.; Kulikova, A.A.; Shpakov, A.O. Intranasal insulin restores metabolic parameters and insulin sensitivity in rats with metabolic syndrome. Bull. Exp. Biol. Med. 2017, 163, 184-189. [CrossRef]

52. Beirami, E.; Oryan, S.; Seyedhosseini Tamijani, S.M.; Ahmadiani, A.; Dargahi, L. Intranasal insulin treatment restores cognitive deficits and insulin signaling impairment induced by repeated methamphetamine exposure. J. Cell. Biochem. 2018, 119, $2345-2355$. [CrossRef]

53. Chaudhary, G.; Sinha, K.; Gupta, Y.K. Protective effect of exogenous administration of alpha-tocopherol in middle cerebral artery occlusion model of cerebral ischemia in rats. Fundam. Clin. Pharmacol. 2003, 17, 703-707. [CrossRef]

54. Balakrishnan, R.; Satish Kumar, C.S.; Rani, M.U.; Srikanth, M.K.; Boobalan, G.; Reddy, A.G. An evaluation of the protective role of alpha-tocopherol on free radical induced hepatotoxicity and nephrotoxicity due to chromium in rats. Indian J. Pharmacol. 2013, 45, 490-495. [CrossRef]

55. Pasantes-Morales, H.; Tuz, K. Volume changes in neurons: Hyperexcitability and neuronal death. Contrib. Nephrol. 2006, 152, 221-240. [CrossRef] [PubMed]

56. Shao, L.R.; Janicot, R.; Stafstrom, C.E. $\mathrm{Na}^{+}-\mathrm{K}^{+}$-ATPase functions in the developing hippocampus: Regional differences in CA1 and CA3 neuronal excitability and role in epileptiform network bursting. J. Neurophysiol. 2021, 125, 1-11. [CrossRef] [PubMed]

57. Kadoya, A.; Miyake, H.; Ohyashiki, T. Contribution of lipid dynamics on the inhibition of bovine brain synaptosomal $\mathrm{Na}^{+}-\mathrm{K}^{+}-$ ATPase activity induced by 4-hydroxy-2-nonenal. Biol. Pharm. Bull. 2003, 26, 787-793. [CrossRef] [PubMed]

58. Miyake, H.; Kadoya, A.; Ohyashiki, T. Increase in molecular rigidity of the protein conformation of brain $\mathrm{Na}^{+}-\mathrm{K}^{+}-\mathrm{ATPase}$ by modification with 4-hydroxy-2-nonenal. Biol. Pharm. Bull. 2003, 26, 1652-1656. [CrossRef] [PubMed]

59. Abdalla, F.H.; Schmatz, R.; Cardoso, A.M.; Carvalho, F.B.; Baldissarelli, J.; de Oliveira, J.S.; Rosa, M.M.; Goncalves Nunes, M.A.; Rubin, M.A.; da Cruz, I.B.; et al. Quercetin protects the impairment of memory and anxiogenic-like behavior in rats exposed to cadmium: Possible involvement of the acetylcholinesterase and $\mathrm{Na}^{+}, \mathrm{K}^{+}$-ATPase activities. Physiol. Behav. 2014, 135, $152-167$. [CrossRef]

60. Mironova, E.V.; Evstratova, A.A.; Antonov, S.M. A fluorescence vital assay for the recognition and quantification of excitotoxic cell death by necrosis and apoptosis using confocal microscopy on neurons in culture. J. Neurosci. Methods 2007, 163, 1-8. [CrossRef] [PubMed]

61. Zorina, I.I.; Bayunova, L.V.; Zakharova, I.O.; Avrova, N.F. The dependence of the protective effect of insulin on its concentration and modulation of ERK1/2 activity under the conditions of oxidative stress in cortical neurons. Neurochem. J. 2018, 10, 111-116. [CrossRef]

62. Vlasova, Y.A.; Zakharova, I.O.; Avrova, N.F. The effect of alpha-tocopherol and $\mathrm{H} 2 \mathrm{O} 2$ on the mitochondrial membrane potential and Bax/Bcl-xL ratio in PC12 cells. Neurochem. J. 2016, 10, 318-322. [CrossRef]

63. Molchanova, S.M.; Moskvin, A.N.; Zakharova, I.Y.; Yurlova, L.A.; Nosova, I.Y.; Avrova, N. Effects of two-vessel forebrain ischemia and of administration of indomethacin and quinacrine on $\mathrm{Na}^{+}, \mathrm{K}^{+}$-ATPase activity in various rat brain areas. J. Evol. Biochem. Physiol. 2005, 41, 39-46. [CrossRef]

64. Folch, J.; Lees, M.; Sloane Stanley, G.H. A simple method for the isolation and purification of total lipides from animal tissues. J. Biol. Chem. 1957, 226, 497-509. [CrossRef]

65. Sarieva, K.V.; Lyanguzov, A.Y.; Galkina, O.V.; Vetrovoy, O.V. The effect of severe hypoxia on HIF1- and Nrf2-mediated mechanisms of antioxidant defense in the rat neocortex. Neurochem. J. 2019, 13, 145-155. [CrossRef] 
66. Ferenczi, S.; Kuti, D.; Cserháti, M.; Krifaton, C.; Szoboszlay, S.; Kukolya, J.; Szőke, Z.; Albert, M.; Kriszt, B.; Kovács, K.J.; et al. Effects of single and repeated oral doses of ochratoxin A on the lipid peroxidation and antioxidant defense systems in mouse kidneys. Toxins 2020, 12, 732. [CrossRef] [PubMed]

67. Avrova, N.F.; Victorov, I.V.; Tyurin, V.A.; Zakharova, I.O.; Sokolova, T.V.; Andreeva, N.A.; Stelmaschuk, E.V.; Tyurina, Y.Y.; Gonchar, V.S. Inhibition of glutamate-induced intensification of free radical reactions by gangliosides: Possible role in their protective effect in rat cerebellar granule cells and brain synaptosomes. Neurochem. Res. 1998, 23, 945-952. [CrossRef] 